\title{
Uniaxial Tensile Deformation And Fracture Process of Structures Forming By Unsaturated Intercalation of Amine Molecule Into C-S-H Gel
}

\section{Dawei sun ( $\sim$ sundawei@bjut.edu.cn )}

Beijing University of Technology https://orcid.org/0000-0003-4703-4737

\section{Yan Zheng}

Beijing University of Technology

Jianhua Yan

Beijing University of Technology

\section{Yali Wang}

Beijing University of Technology

Jianfeng Wang

Beijing University of Technology

Mingzhang Lan

Beijing University of Technology

\section{Ziming Wang}

Beijing University of Technology

\section{Zherui Chen}

Beijing University of Technology

\section{Suping Cui}

Beijing University of Technology

\section{Zhiyong Wang}

Northeastern University

\section{Research Article}

Keywords: Amine molecules, Unsaturated intercalation, Molecular dynamics, Visco-elastic behavior, Deformation and fracture process

Posted Date: August 11th, 2021

DOI: https://doi.org/10.21203/rs.3.rs-764081/v1

License: (a) (i) This work is licensed under a Creative Commons Attribution 4.0 International License. Read Full License 
Version of Record: A version of this preprint was published at Journal of Molecular Modeling on January 1st, 2022. See the published version at https://doi.org/10.1007/s00894-021-04998-5. 


\section{Abstract}

The application of cement based materials in engineering requires the understanding of their characteristics and subsequent deformation and fracture process of C-S-H gel in service. In this work, three types of amine molecules including TEPA, PAM and TEA were intercalated unsaturatedly into C-S$\mathrm{H}$ gel successfully. Systematical analysis was performed on the structures and properties on both $\mathrm{C}-\mathrm{S}-\mathrm{H}$ gel and corresponding amine molecules / C-S-H gel. It was found that unsaturated intercalation of amine molecules into $\mathrm{C}-\mathrm{S}-\mathrm{H}$ gel plays a key role in the geometry and therein density of nanocomposites. Subsequently, radial distribution function (RDF), time correlated function (TCF) and mean square displacement (MSD) were applied to characterize the structure and dynamic information of the asgenerated nanocomposites, demonstrating the occurance of interaction between amine molecules with $\mathrm{Ca}-\mathrm{Si}$ layer and acceleration of water diffusion by unsaturated intercalation of amine molecules into the interlayer region in $\mathrm{C}-\mathrm{S}-\mathrm{H}$ gel. Finally, deformation and fracture process of $\mathrm{C}-\mathrm{S}-\mathrm{H}$ gel and amine molecules / C-S-H gel under uniaxial tensile loads were displayed by molecular dynamics simulation. It was indicated that Young's modulus of nanocomposites demonstrates a strain softening nature, indicating a visco-elastic behavior. The breakage of $\mathrm{Ca}-\mathrm{O}$ bonds and hydrogen bonds dominates the fracture of $\mathrm{C}-\mathrm{S}-\mathrm{H}$ gel. Weak interaction for TEPA / C-S-H gel or TEA / C-S-H gel leads to a decreased tensile strength. Local stress concentration in other interlayer region governs the deformation and fracture process in spite of the formation of strong interaction between double bonded polar oxygen atoms in PAM molecules and $\mathrm{Ca}$ atoms in $\mathrm{C}-\mathrm{S}-\mathrm{H}$ gel.

\section{Introduction}

Cement based materials have attracted great interests due to their wide application potentials in various infrastructures such as airport pavement, harbor wharf, dam foundation and so on ${ }^{1-4}$. As the most important hydration products, calcium silicate hydrate $(\mathrm{C}-\mathrm{S}-\mathrm{H})$ gel plays an essential role in durability and mechanical stability of cement based materials ${ }^{5-6}$. For instance, the workability, ductility, rigidity and thermal stability have been significantly improved by successful implementation of organic molecules to cement based materials ${ }^{7-8}$, among which amine molecules demonstrate their advantanges especially as water reducing agents, early strength agents or retarder ${ }^{9-11}$. To enable the use of amine molecules in the cement based materials, it is necessary to explore not only the interaction mechanism between amine molecules and $\mathrm{C}-\mathrm{S}-\mathrm{H}$ gel, but the mechanical properties of amine / $\mathrm{C}-\mathrm{S}-\mathrm{H}$ nanocomposites.

A portion of studies have been conducted to investigate the interaction of organic molecules with $\mathrm{C}-\mathrm{S}-\mathrm{H}$ gel, among which surface grafting ${ }^{9,12-13}$, chemical bonding ${ }^{14-16}$ and intercalation ${ }^{13,17-18}$ are the most prevailing methodologies. According to the foregoing techniques, research indicates that durability and mechanical properties of $\mathrm{C}-\mathrm{S}-\mathrm{H}$ gel can be advanced effectively, thus attracting numerous attentions 19-25. Consequently, it was found that the basal space of $\mathrm{C}-\mathrm{S}-\mathrm{H}$ gel expanded when the organic molecules intercalated into the layered structures of $\mathrm{C}-\mathrm{S}-\mathrm{H}$ gel ${ }^{26-27}$. Moreover, permeability, durability 
and volume stability of $\mathrm{C}-\mathrm{S}-\mathrm{H}$ gel / polymer nanocomposites in solutions can be tailored by molecules intercalation, giving rise to a long-term performance in cementitious materials ${ }^{1,24-25,28-29}$. For example, polyaniline limits the diffusion of harmful ions into $\mathrm{C}-\mathrm{S}-\mathrm{H}$ gel for a better durability of cement based materials ${ }^{30}$. Meanwhile, it is noteworthy that critical physical features such as elasticity, yielding, creep, hysteresis and even toughening behavior demonstrate outstanding performances in service due to the developed processing techniques, especially the well-suited molecules intercalation methodology $2,16,23$, 31-32. Therefore, intercalation of organic molecules into $\mathrm{C}-\mathrm{S}-\mathrm{H}$ gel provides an efficient way to prepare hydration products with improved performance.

To achieve various novel functionality, amine molecules often play a key role in cement based materials. In epoxy-amine self-healing systems, the encapsulated epoxy resin and dispersed linear amines (tetraethylene pentamine, TEPA) in the cement based materials can greatly influence both the structures and properties of $\mathrm{C}-\mathrm{S}-\mathrm{H}$ gel ${ }^{4,33-34}$. As amide molecules, carbnyl and amine functional groups in polyacrylamide (PAM) could serve as reology and mechanical properties modifiers ${ }^{20-21}$. In addition, the workability of cement based materials can be dramitically improved by introduced triethanolamines (TEA) as grinding aids, early strength agents or hydration retarder, drawing many inestigators ${ }^{10,21}$. As yet, debate continues due to the undeveloped interaction mechanism between amine molecules and C$\mathrm{S}-\mathrm{H}$ gel under saturated intercalation conditions. It should be realized that amine molecules cannot intercalate into every layerred space of cement based materials in practice. It is thus necessary to invesigate the interaction between amine molecules and $\mathrm{C}-\mathrm{S}-\mathrm{H}$ gel, especially under unsaturated intercalation situations.

However, it is usually experimentally difficult to detail the interaction mechanism. Numerical simulation offers an another way to provide quantitative information about structure, energy and dynamic process of materials at atomic level. Research has been performend on the interaction between $\mathrm{C}-\mathrm{S}-\mathrm{H}$ gel and organic molecules according to molecular dynamics (MD) technique $7,10,18,30,35-36$. It was found that the combination of organic molecules and $\mathrm{C}-\mathrm{S}-\mathrm{H}$ gel leads to materials with excellent mechanical performance macroscopically ${ }^{18}$. The additional polyacrylic acid (PAA), polyvinyl alcohol (PVA) or polyethylene glycol (PEG) in the $\mathrm{C}-\mathrm{S}-\mathrm{H}$ gel enables the improvement of tensile strength, elastic modulus and ductility based on molecular simulations ${ }^{16}$. However, there is a lack of studies on the interaction behavior between amine molecules and $\mathrm{C}-\mathrm{S}-\mathrm{H}$ gel, especially the effect of unsaturated intercalation of branched amine molecules into $\mathrm{C}-\mathrm{S}-\mathrm{H}$ gel on the structures and properties of nanocomposites.

The aim of this work was to investigate the influence of amine molecules (TEPAs, PAMs and TEAs) on the structure and mechanical properties of $\mathrm{C}-\mathrm{S}-\mathrm{H}$ gel under unsaturated intercalation conditions by means of molecular dynamics method, in which interlayer space size, density distribution, RDF, TCF and MSD were applied to analyze structure and dynamic information of amine molecules / C-S-H gel nanocomposites. Finally, uniaxial tensile simulation were performed on amine molecules / $\mathrm{C}-\mathrm{S}-\mathrm{H}$ gel to obtain the mechanical properties such as Young's modulus and tensile strength along with deformation and failure process. This investigation would faciliate the deep understanding of the structural 
information of amine molecules / C-S-H gel, thus guiding for the improvement of cement based materials practically.

\section{Numerical Simulation Procedure}

\subsection{Molecular dynamics modelling}

The construction of $\mathrm{C}-\mathrm{S}-\mathrm{H}$ gel model was performed in large-scale atomic / molecular massively parallel simulator (LAMMPS) according to Pellenq's real model derived from tobermorite 11 ^ with Ca / Si ratio of 1.3 followed by the addition of amine molecules into the interlayer space of $\mathrm{C}-\mathrm{S}-\mathrm{H}$ gel ${ }^{4,37}$. The sturctures of amine molecules are shown in Fig. 1, from which it can be seen that there is a linear structure in TEPA molecule (refer to Fig. 1a), and dendritic ones in both PAM molecule (refer to Fig. 1b) and TEA molecule (Fig. 1c). Meanwhile, it should be noted that the number of carbon atoms varies from amine molecules. To maintain the balance constituents for carbon atoms of amine molecules in $\mathrm{C}-\mathrm{S}-\mathrm{H}$ gel, the numbers of amine molecules were assigned 1,1 , and 2 in the interfacial space of $\mathrm{C}-\mathrm{S}-\mathrm{H}$ gel for TEPA, PAM and TEA, respectively.

Thereafter, water molecules were implemented into the $\mathrm{C}-\mathrm{S}-\mathrm{H}$ gel model until saturation through Grand Canonical Maonte Carlo (GCMC) method, which were widely applied in water absorption of $\mathrm{C}-\mathrm{S}-\mathrm{H}$ gel models ${ }^{4,32,38}$. In this process, it is tantamount to place the dry $\mathrm{C}-\mathrm{S}-\mathrm{H}$ gel model into an immaginary infinite reservoir full of liquid water with a density of $1 \mathrm{~g} / \mathrm{cm}^{3}$ under a temperature of $300 \mathrm{~K}$. The whole simulation process contained $10^{8}$ cycles of equilibration run and subsequent $2 \times 10^{8}$ cycles of production run. For each cycle, the $\mathrm{C}-\mathrm{S}-\mathrm{H}$ gel model experienced 1000 attempts on water molecules to insert, delete, displace and rotate. Subsequently, molecular dynamics analysis was performed on both $\mathrm{C}-\mathrm{S}-\mathrm{H}$ gel and amine molecules / C-S-H gel, in which structure equilibrium was achieved through 3000 ps NPT ensemble followed by another 3000 ps to obtain the atomic trajectories, forming the unsaturated intercalation status for further analysis on structures, properties and even deformation and fracture behaviors.

\subsection{Uniaxial tensile experiments}

The representative molecular structures for $\mathrm{C}-\mathrm{S}-\mathrm{H}$ gel model, TEPA / C-S-H gel model, PAM / C-S-H gel model and TEA / C-S-H gel model were in a cubical shape with respective dimensions of $1.188 \AA \mathrm{x}$ $1.180 \AA x+1.212 \AA, 1.184 \AA x 1.176 \AA x 1.208 \AA, 1.259 \AA x 1.251 \AA x 1.285 \AA$ and $1.197 \AA x 1.188 \AA x 1.221$ $\AA$. Deformation simulations were performed on LAMMPS software to explore the fracture process of the as-generated molecular structures subjected to a uniaxial tensile load at a strain rate of $0.008 / \mathrm{ps}$. It should be realized that displacement control was used to apply the tensile load on one end of model perpendicular to the loading direction; while the other was set to be fixed in the loading direction. With the consideration of Possion's effect during tension simulation, lateral faces parallel to the loading direction were assign to a free motion property. As a result, tensile stress-strain behaviors of different amine molecules / C-S-H gel models can be obtained, thus determining the corresponding Young's modulus 
and tensile strength. In this study, Young's modulus and tensile strength are defined as the slope and maximum stress of the stress-strain behavior, respectively.

\subsection{Chacterization methodology}

In the present study, the interaction between different atoms was described by Lennard-Jones fuction and coulomibic term. The intramolecule interaction was represented by taking bond length, bond angles, torsion angles and out-of-plane agnles into account. It is noteworthy that the combination of Clayff force field (detail parameters can be found in our previous study ${ }^{4}$ ), single point charge (SPC) and consistent valence force field (CVFF) was applied to investigate the interaction between organic molecules, water molecules and $\mathrm{C}-\mathrm{S}-\mathrm{H}$ gels due to the advantages of the Clayff force field to describe the structure and properties of $\mathrm{C}-\mathrm{S}-\mathrm{H}$ gel ${ }^{22}$, SPC to determine the interactions between water molecules ${ }^{18}$ and CVFF to fit small organic molecules thus exploring the interaction between proteins and organic systems ${ }^{4,16}$.

\section{Results And Discussion}

\subsection{Representative molecular structures in simulation}

The representative molecular structures for $\mathrm{C}-\mathrm{S}-\mathrm{H}$ gel and amine molecules / $\mathrm{C}-\mathrm{S}-\mathrm{H}$ gel are presented in Fig. 2, according to which systematic analysis is performed on the molecular structrual features of the as-generated models. Among these models, it should be noted that calcium atoms in intralayer region and interlayer region are labelled as Ca_intral and Ca_interl, respectively. There are two types of oxygen atoms linking with silicon atoms. One is bridging oxygen in silica chain, denoting as O_bri; the other is non-bridging in silica chain, denoting as 0 nbri. The oxygen atoms in water molecules are described as O_water. By the way, organic molecules also contain atoms such as nytrogen $(\mathrm{N})$, oxygen (O), carbon (C) and hydrogen $(\mathrm{H})$. It is found that Ca_intral atom could form polyhedron with its surrounding O_nbri atoms as $\mathrm{Ca}-\mathrm{Si}$ layer. Meanwhile, there are still additional water molecules in the intralayer region due to the diffusion of water molecules in the interlayer region through the defective silicate chains. The interlayer region exists in between two different $\mathrm{Ca}$-Si layers, in which there are massive Ca_interl atoms, water molecules and amine molecules. It can be seen that amine molecule locates at the interlayer region of the corresponding model (refer to Fig. 2b-d). The effect of amine molecules intercalated into the interlayer region on the geometrical size and chemical environment will be detailed in the following sections.

\subsection{Characterization of unsaturated intercalated amine molecules into $\mathrm{C}-\mathrm{S}-\mathrm{H}$ gel}

\subsubsection{Effect of amine molecules on geometrical size of nanocomposites}

The existance of amine molecules in the interlayer region induces the change of model size. As can be seen from Fig. 3a that the space length varies from amine molecules. The baseline model is based on the 
as-generated C-S-H gel model with a dimension of $1.188 \AA \times 1.180 \AA \times 1.212 \AA$. Compared with C-S-H gel model, geometrical lengths for amine molecules / C-S-H gel models change in all $\mathrm{x}, \mathrm{y}$ and $\mathrm{z}$ directions (Cartesian coordinate system refers to Fig. 2), different from a recent study that charactersitic length only elongated in $\mathrm{z}$ direction ${ }^{16}$. However, the geometrical size of amine molecules / C-S-H gel model illustrates a molecular structure dependence. With the intercalation of linear TEPA molecule into pure $\mathrm{C}-\mathrm{S}-\mathrm{H}$ gel, the stable TEPA / C-S-H gel model demonstrates a dimension of $1.184 \AA$ × $1.176 \AA$ × $1.208 \AA$, a slight shrinkage in all $x, y$ and $z$ directions due to the interaction of polar amine functional groups with the opposite $\mathrm{Ca}-\mathrm{Si}$ layer. Unlike TEPA / C-S-H gel model, the intercalation of branched PAM and TEA molecules into pure $\mathrm{C}-\mathrm{S}-\mathrm{H}$ gel leads to a volume expansion. For instance, the dimensions for PAM / C-S-H gel and TEA / C-S-H gel models increases to $1.259 \AA \times 1.251 \AA \times 1.285 \AA$ and $1.197 \AA \times$ $1.188 \AA \times 1.221 \AA$, respectively. Compared to pure $\mathrm{C}-\mathrm{S}-\mathrm{H}$ gel model, the dimensions of PAM / C-S-H gel model in all $\mathrm{x}, \mathrm{y}$ and $\mathrm{z}$ directions increases more than those of TEA / $\mathrm{C}-\mathrm{S}-\mathrm{H}$ gel model due to the greater steric hindrance of PAM molecule, which repells the $\mathrm{Ca}$-Si layer more seriouly, thus forming a large interlayer region (refer to Fig. 2). As known, density of material is a function of volume for a given mass. The change of model volume in this study would bring a variation of density of nanopcomposites. As can be seen in Fig. $3 b$ that the density for $\mathrm{C}-\mathrm{S}-\mathrm{H}$ gel, TEPA / C-S-H nanocomposite, PAM / C-S-H nanocomposite and TEA / C-S-H nanocomposite would be $2.26 \mathrm{~g} / \mathrm{cm}^{3}, 2.27 \mathrm{~g} / \mathrm{cm}^{3}, 1.92 \mathrm{~g} / \mathrm{cm}^{3}$ and $2.23 \mathrm{~g} / \mathrm{cm}^{3}$, respectively. As stated above, density is reciprocal to volume, indicating a same intrisinc mechanism. Therefore, amine molecular structures dominates the change of geometrical size and subsequent density of composite materials.

\subsubsection{Effect of amine molecules onatom distribution of nanocomposites}

As can be seen clearly in Fig. 2 that the unsaturated intercalated amine molecules into the layered $\mathrm{Ca}-\mathrm{Si}$ structures interact with atoms in $\mathrm{C}-\mathrm{S}-\mathrm{H}$ gel, forming different bonds. Figure 4 gives the intensity distribution of $\mathrm{Ca}$ _intral, $\mathrm{Ca}$ _interl, $\mathrm{Si}$, O_water and $\mathrm{O}$ atoms or $\mathrm{N}$ atoms in amine molecules along $\mathrm{z}$ direction. It can be seen from Fig. 4 a that $\mathrm{Ca}$ intral atoms and $\mathrm{Si}$ atoms distribute in a much more orderly manner due to the existance of sharp peaks, constructing the Ca-Si layer of $\mathrm{C}-\mathrm{S}-\mathrm{H}$ gel model. The region between two Ca_intral layer is defined as the interlayer region. Sharp peaks of Ca_interl atoms are observed in the interlayer region, implying Ca_interl atoms were mainly located at interlayer region. Besides, water molecules distribute in a relatively irregular way in the interlayer region of $\mathrm{C}-\mathrm{S}-\mathrm{H}$ gel model (refer to Fig. 4a), due to its diffusion capability through the defective region. However, the intercalation of amine molecules into $\mathrm{C}-\mathrm{S}-\mathrm{H}$ gel enables the appearance of minor sharp peaks of Ca_interl atoms, oxygen atoms and water molecules in the interlayer region (refer to Fig. $4 \mathrm{~b}-\mathrm{d}$ ). This is due to the fact that polar functional groups in amine molecules break the equilibrium between atoms in the interlayer region, therein affecting atom distributions. In the meantime, it should be realized that atom distributions show amine molecule dependent characteristics towards calcium-silicate region (refer to Fig. 4b-d). In other words, the structure of amine molecule plays a crucial role in atom distributions. It also can be seen from Fig. $4 \mathrm{~b}$ that the interaction between $\mathrm{N}$ atoms and $\mathrm{Ca}$ atoms promotes $\mathrm{N}$ atoms 
distributed close to the surface of Ca-Si layer in the TEPA / C-S-H gel model. In addition, no penetration of TEPA molecules into $\mathrm{Ca}-\mathrm{Si}$ layer occurs due to rigidity of TEPA molecules. Similar to TEPA molecule in $\mathrm{C}-\mathrm{S}-\mathrm{H}$ gel, $\mathrm{N}$ atoms and $\mathrm{O}$ atoms in respective PAM and TEA molecules locate in the vicinity of $\mathrm{Ca}-\mathrm{Si}$ layer as well, having better physical bonding strength. However, the $\mathrm{N}$ atoms of PAM molecule and Oxygen atoms of TEA molecule distributed closing to both Ca-Si layer in the interlayer region(refer to Fig. $4 \mathrm{c}$ and Fig. 4d). In comparison, the $\mathrm{N}$ atoms of TEPA moleculs were mainly gathering adjoining to one Ca-Si layer. All these characteristics affect greatly the final tensile strength of composites.

\subsection{Interfacial bonding properties in the nanocomposites 3.3.1 Interaction between $\mathrm{Ca}$ atoms and $\mathrm{O}$ atoms}

Radial distribution function (RDF) is widely accepted to represent spatial structure to describe the interaction between $\mathrm{Ca}$ atoms and $\mathrm{O}$ atoms in the nanocomposites. Figure 5 gives the RDF curves between $\mathrm{Ca}$ atoms and $\mathrm{O}$ atoms in $\mathrm{C}-\mathrm{S}-\mathrm{H}$ gel, TEPA / C-S-H gel, PAM / C-S-H gel and TEA / C-S-H gel, respectively. As shown in Fig. 5a, both $\mathrm{Ca}$ _intral atoms and $\mathrm{Ca}$ _interl atoms could form stable bonds with O_nbri atoms. The bond lengths for Ca_intral-O_nbri and Ca_interl-O_nbri are $2.35 \AA$ And $2.45 \AA$, respectively. Compared to Ca_interl-0_nbri, bond length for Ca_intral-O_nbri is smaller due to more charges of $\mathrm{Ca}$ intral atoms leading to greater interatomic forces, thus a shorter bond length. It is interesting to see that bond lengths for Ca_intral-O_nbri and Ca_interl-O_nbri remain unchanged even if there are intercalations of TEPA (refer to Fig. 5b), PAM (refer to Fig. 5c) and TEA (refer to Fig. 5d) molecules into $\mathrm{C}-\mathrm{S}-\mathrm{H}$ gel, implying a minor influence of amine molecules on bond length. However, the introduction of amine molecules into $\mathrm{C}-\mathrm{S}-\mathrm{H}$ gel can change the coordination number of $\mathrm{Ca}-\mathrm{O}$ bonds. As listed in Table 1, the coordination numbers of interaction pair Ca_intral-0_nbri are 4.24, 4.38, 4.04 and 4.36 for C-S-H gel, TEPA / C-S-H gel, PAM / C-S-H gel and TEA / C-S-H gel, respectively. At the same time, the coordination numbers of interaction pair Ca_interl-O_nbri are 2.50, 2.68, 2.66 and 2.67 for the corresponding aforementioned nanocomposites. In addition, only a small amount of Ca_interl atoms could form bonds with O_bri atoms due to the large steric hindrance of O_bri atoms. As shown in Fig. 5a, there are no peaks in the Ca_intral-O_bri curves in the $\mathrm{C}-\mathrm{S}-\mathrm{H}$ gel model, indicating that Ca_intral atoms form no bonds with O_bri atoms. It is noteworthy that minor peaks appear as illustrated in Fig. $5 b$-d due to the intercalation of amine molecules into $\mathrm{C}-\mathrm{S}-\mathrm{H}$ gel, which disturbed the arrangment of $\mathrm{Ca}-\mathrm{Si}$ layers thus giving more space for the formation of Ca_intral-O_bri bonds. 
Table 1

Coordination number of interaction pairs in C-S-H gel, TEPA / C-S-H gel, PAM / C-S-H gel and TEA / C-S-H gel

\begin{tabular}{|lllll|}
\hline Interaction pair & \multicolumn{4}{l|}{ Coordination No. } \\
\cline { 2 - 5 } & C-S-H gel & TEPA / C-S-H gel & PAM / C-S-H gel & TEA / C-S-H gel \\
\hline Ca_intral-O_nbri & 4.24 & 4.38 & 4.04 & 4.36 \\
\hline Ca_interl-O_nbri & 2.50 & 2.68 & 2.66 & 2.67 \\
\hline Ca_intral-O_water & 1.70 & 1.47 & 1.37 & 1.65 \\
\hline Ca_interl-O_water & 3.40 & 3.11 & 2.80 & 3.11 \\
\hline O_nbri-H_water & 1.06 & 0.96 & 0.93 & 0.98 \\
\hline 3.2 Interaction between Water molecules and C-S-H gel
\end{tabular}

Apart from that, the intercalation of amine molecules into $\mathrm{C}-\mathrm{S}-\mathrm{H}$ gel affects the interaction between $\mathrm{C}-$ S-H gel and water molecules as well. In the models of $\mathrm{C}-\mathrm{S}-\mathrm{H}$ gel (refer to Fig. 6a), TEPA / C-S-H gel (refer to Fig. 6b) and TEA / C-S-H gel (refer to Fig. 6d), the bond lengths for Ca_intral-O_water, Ca_interl-O_water and O_nbri-H_water are respective $2.45 \AA$, $2.55 \AA$ and $1.65 \AA$, implying a nearly constant bond length in spite of addition of TEPA and TEA molecules. In comparison, the bond lengths for Ca_intral-O_water, Ca_interl-O_water and O_nbri-H_water are respective $2.65 \AA$, $2.65 \AA$ and $1.95 \AA$ in the model of PAM / C-S-H gel (refer to Fig. 6c), demonstrating a weakened interaction between substrates and water molecules due to the addition of PAM molecules in $\mathrm{C}-\mathrm{S}-\mathrm{H}$ gel. Since PAM molecules contained double bonded oxygen atoms with strong polarities to enable water molecules move away from substrates, thus leaving a longer bonds. It can be seen from Fig. 6 (a, b, c, d) that there is no strong bond formation between O_bri atoms and water molecules as there is no obvious peak in RDF curve for all models.

As widely accepted, coordination number is an important parameter to characterize the influence of amine molecules on $\mathrm{C}-\mathrm{S}-\mathrm{H}$ gel chemical structures. It can be seen from Table 1 that in pure $\mathrm{C}-\mathrm{S}-\mathrm{H}$ gel, coordination numbers for interaction pairs Ca_intral-O_water, Ca_interl-O_water and O_nbri-H_water are $1.70,3.40$ and 1.06 , respectively. It is interesting to observe that the intercalation of amine molecules into $\mathrm{C}-\mathrm{S}-\mathrm{H}$ gel leads to a decrease in coordination number (refer to Table 1). However, the minimum coordination numbers for all the interaction pairs in PAM / C-S-H gel (refer to Table 1) result from the large steric hindrance and strong polar oxygen atoms, which affect the interaction between $\mathrm{C}-\mathrm{S}-\mathrm{H}$ gel and water molecules more seriously, thus giving rise to a lower coordination number.

\subsubsection{Interaction between amine molecules and $\mathrm{C}-\mathrm{S}-\mathrm{H}$ gel}

As illustrated in Fig. 7, amine molecules not only influence the chemical structures of $\mathrm{C}-\mathrm{S}-\mathrm{H}$ gel, but also interact with $\mathrm{C}-\mathrm{S}-\mathrm{H}$ gel. The hydrogen bonds are calculated according to the rules in our previous publication ${ }^{4}$. It can be seen from Fig. 7a that Ca_interl atoms could form strong bonds with $\mathrm{N}$ atoms in 
TEPA with a bond length of $2.65 \AA$ and coordination number of 0.08 . However, there is no bond forming between $\mathrm{Ca}$ _intral atoms and $\mathrm{N}$ atoms in TEPA due to the reason that most of $\mathrm{Ca}$ _intral atoms get caught in the polyhedral of $\mathrm{Ca}-\mathrm{Si}$ layer. Although no obvious peaks were observed in O_bri-H@N $\mathrm{N}_{(\mathrm{TEPA})}$ and O_nbri-H@N $\mathrm{N}_{(\mathrm{TEPA})}$, the active hydrogen atoms in TEPA molecules still could form hydrogen bonds with O_bri or O_nbri atoms, either. Averagely, each TEPA molecule could form 0.628 and 0.485 hydrogen bonds with O_nbri and O_bri atoms, respectively (Table 2).In contrast, both Ca_intral atoms and Ca_interl atoms could form strong bonds with 0 atoms in PAM molecules with the same bond length of $2.55 \AA$. Nevertheless, there is a difference between the coordination numbers, which are 0.01 for Ca_intral-O bonds and 0.04 for $\mathrm{Ca}$ _interl- $\mathrm{O}$ bonds. The higher coordination number indicates that the distribution of Ca_interl atoms locates at the interlayer region, thus offering more opportunity to encounter the 0 atoms. As shown in Fig. 7b, $\mathrm{Ca}$ atoms in intralayer regions could not form bonds with $\mathrm{N}$ atoms in PAM molecules, but Ca_interl atoms could form bonds with length of $2.95 \AA$, which is longer than the bonds between $\mathrm{Ca}$ _interl atoms and $\mathrm{N}$ atoms of TEPA molecules, because of the lower polarity and negaelectricity of the linkage between $\mathrm{N}$ atoms in PAM molecules and carbonyl groups. Besides, the active hydrogen atoms in PAM molecules could bond with O_nbri atoms and O_bri atoms through hydrogen bonding, and each PAM molecule could bond averagely 0.056 O_bri atoms and 1.082 O_nbri atoms (Table 2). Note that the amount of O_bri atoms involved hydrogen bonds was far lower than that between O_nbri involved hydrogen atoms due to its large steric hindrance.

Table 2

Coordination number of hydrogen bonds forming between amine molecules and $\mathrm{C}-\mathrm{S}-\mathrm{H}$ gel

\begin{tabular}{|llll|}
\hline Interaction pair & \multicolumn{3}{l}{ Coordination No. } \\
\cline { 2 - 5 } & TEPA & PAM & TEA \\
\hline O_bri-H@N & 0.628 & 0.00548 & - \\
\hline O_nbri-H@N & 0.485 & 1.082 & - \\
\hline O_water-H@N & 0.78 & 0.06 & - \\
\hline O_bri-H@O & - & - & 0.0015 \\
\hline N-H_water & 0.346 & 0.137 & 0 \\
\hline O-H_water & - & 0.567 & 0.961 \\
\hline O_nbri-H@O & - & - & 1.62 \\
\hline O_water-H@O & - & - & 0.33 \\
\hline
\end{tabular}

In TEA / C-S-H gel nanocomposites (refer to Fig. 7c), Ca_intral atoms could form minor bonds (bond length: $2.55 \AA$, coordination number: 0.01 ) with $\mathrm{O}$ atoms rather than $\mathrm{N}$ atoms in TEA molecules due to the lower polarity and higher steric hindrance of $\mathrm{N}$ atoms. Different from $\mathrm{Ca}$ _intral atoms, Ca_interl atoms could form bonds with both 0 atoms (bond length: $2.65 \AA$, coordination number: 0.09 ) and $N$ atoms 
(bond length: $2.65 \AA$, coordination number: 0.04 ) in TEA molecules, whose bond lengths and coordination numbers are greater than those of $\mathrm{Ca}_{-}$intral involved bonds on account of more Ca_interl atoms than Ca_intral atoms providing additional opportunities to encounter and bond with TEA molecules. As stated above that coordination number for interaction pair Ca_interl-0@TEA is greater than that for Ca_interlN@TEA for the reason that $\mathrm{O}$ atoms distributed at the ends of TEA molecule chain have smaller steric hindrance than $\mathrm{N}$ atoms entrapped in the core part of TEA molecules. Besides, the active hydrogen atoms of TEA molecules could form hydrogen bonds with O_bri atoms and O_nbri atoms. Averagely, each TEA molecule could form 0.002 hydrogen bonds with O_bri atoms, and 1.62 hydrogen bonds with O_nbri atoms.

By comparison, TEPA, PAM and TEA molecules prefer to bonding with $\mathrm{C}-\mathrm{S}-\mathrm{H}$ substrates than calcium atoms.

\subsubsection{Interaction between amine molecules with water molecules}

Besides formation of hydrogen bonds with the $\mathrm{Ca}-\mathrm{Si}$ layer, the amine molecules could also form hydrogen bonds with surrounding water molecules. The number of hydrogen bonds between amine molecules and water molecules was calculated based on our previous publication ${ }^{4}$. Figure 8 describes the radial distribution function (RDF) between amine molecules and water molecules. It can be concluded that there is no sharp peaks of $\mathrm{O}_{-}$water $-\mathrm{H}_{\text {(TEPA) }}$ and $\mathrm{H}_{\text {Lwater }}-\mathrm{O}_{(\text {TEPA }}$ curves within distance of $2.45 \AA$ in the Fig. 8a, implying no regular arrangement of water molecules around $\mathrm{NH}$ functional groups of TEPA molecules. Averagely, each TEPA molecule could form 1.126 hydrogen bonds with water molecules (refer to Table 2). Figure $8 \mathrm{~b}$ showed the RDF curves between PAM molecules and water molecules. Similarly, no obvious peaks are observed within $2.45 \AA$, indicating that no regular arrangement of water molecules was observed around $\mathrm{N}, \mathrm{O}$, active $\mathrm{H}$ atoms of PAM molecules. Averagely, each PAM molecule could form 0.764 hydrogen bonds with water molecules (refer to Table 2). However, the hydroxyl groups of TEA molecules could form strong interaction with water molecules through hydrogen bonding, but $\mathrm{N}$ atoms could not form hydrogen bonds with them due to large steric hindrance (refer to Fig. 8c). The oxygen atoms and active hydrogen atoms in TEA molecule could form strong interaction with water molecules, because hydroxyl groups are located on the tail of TEA molecules and have smaller steric hindrance to contact with surrounding water molecules. On average, each TEA molecule could form 1.291 hydrogen bonds with water molecules. By comparison, amine molecules with different structures could form various amount of hydrogen bonds with water molecules. It can be seen in Table 2 that the number of hydrogen bonds between TEA and water molecules is maximum, while that between PAM and water molecules is minimum. The influence of hydrogen bonds on the diffusion of water molecule in models will be discussed in Sect. 3.3.5.

\subsubsection{Time correlated dynamic property}

Characterization of the stability of bonds between amine molecules and $\mathrm{C}-\mathrm{S}-\mathrm{H}$ gel (refer to Fig. 9a) or water molecules (refer to Fig. 9b) can be described in terms of time correlated function (TCF) in the 
following Eq. 4, 39-40.

$c(t)=\frac{\langle\delta b(t) \delta b(0)\rangle}{\langle\delta b(0) \delta b(0)\rangle}$

where $\delta b(t)=b(t)<b>$, in which $\langle b\rangle$ is the ensemble average of all $b(t)$ values, in which $b(t)$ is a binary function at the moment $t, b(t)=1$ if two atoms bond together, otherwise $b(t)=0$. Note that TCF value ranges from 0 to 1 . The greater TCF value indicates a higher bonding strength, thus a more stable bond.

Figure 9 illustrates the TCF values of bonds between amine molecules and $\mathrm{C}-\mathrm{S}-\mathrm{H}$ gel. It can be seen from Fig. 9a that $\mathrm{N}$ atoms in TEPA molecules, $\mathrm{N}$ atoms in PAM molecules, $\mathrm{O}$ atoms in PAM molecules and $\mathrm{O}$ atoms in TEA molecules could form stable bonds with $\mathrm{Ca}$ _interl atoms in such a sequence of stability that Ca_interl- $\mathrm{N}_{(\text {TEPA })}>$ Ca_interl $-\mathrm{N}_{(\text {PAM })}>$ Ca_interl $-\mathrm{O}_{(\text {PAM })}>$ Ca_interl $-\mathrm{N}_{(\text {TEA })}>$ Ca_interl $-\mathrm{O}_{(\text {TEA })}$.

As shown in Fig. 9b that no hydrogen bond forms between water molecules and TEPA molecule or PAM molecules. The lower TCF value of hydrogen bonds than that of $\mathrm{Ca}_{-}$interl $-\mathrm{O}_{(\mathrm{TEA})}$ bonds or $\mathrm{O}_{-}$nbri$\mathrm{H} @ \mathrm{O}_{(\mathrm{TEA})}$ indicates a lower strength of hydrogen bonds than that of $\mathrm{Ca}$ _interl- $\mathrm{O}_{(\mathrm{TEA})}$ bonds or O_nbri$\mathrm{H} @ \mathrm{O}_{(\mathrm{TEA})}$. Meanwhile, the slightly higher TCF value of $\mathrm{O}_{-}$water-H@O $\mathrm{O}_{(\mathrm{TEA})}$ than that of $\mathrm{H}_{-} w a t e r-0 @ \mathrm{H}_{\text {(TEA) }}$ implies more stable bonds. Therefore, it can be concluded that bonds between Ca_interl and $\mathrm{O}_{(\mathrm{PAM})}$ or $\mathrm{O}_{(\text {TEA) }}$ make a key contribution on the interactions between $\mathrm{C}-\mathrm{S}-\mathrm{H}$ gel and PAM or TEA molecules corresponding to the observation of obvious peaks in Fig. 7b and Fig. 7c, respectively. However, the simultaneous formations of interaction pairs (Ca_interl- $\mathrm{N}_{(\mathrm{TEA})}, \mathrm{Ca}$ _interl- $\mathrm{O}_{(\mathrm{TEA})}, \mathrm{O}_{-}$nbri-H@O $\mathrm{O}_{(\mathrm{TEA})}$, O_water-H@O $\left(\right.$ TEA),$H_{-}$water-O $\left.@ \mathrm{H}_{(\mathrm{TEA})}\right)$ in the TEA molecules occur as illustrated in Fig. 9, probably influencing the final mechanical properties of nanocomposites. It also can be seen from Fig. 7 that the major interaction pairs for TEPA / C-S-H gel, PAM / C-S-H gel and TEA / C-S-H gel are Ca_interl$\mathrm{N}_{(\text {TEPA) }}$, Ca_interl- $\mathrm{O}_{(\text {PAM })}$ and Ca_interl- $\mathrm{N}_{(\text {TEA) }}$, respectively. Though the stability of Ca_interl- $\mathrm{N}_{\text {(TEPA) }}$ bonds is better than that of $\mathrm{Ca}_{-}$interl $-\mathrm{O}_{(\text {PAM) }}$ bonds (refer to Fig. 9), the bond length for Ca_interl- $\mathrm{O}_{(\text {PAM) }}$ $(2.55 \AA)$ is shorter than that of either Ca_interl- $\mathrm{N}_{\text {(TEPA) }}(2.65 \AA)$ or Ca_interl- $\mathrm{N}_{\text {(TEA) }}(2.65 \AA)$, indicating a stronger bonding strength. As demonstrated in Fig. 9a as well, the formation of hydrogen bonds between atcitive hydrogen atoms in TEA molecules and O_nbri atoms leads to a larger TCF value than Ca_interl$\mathrm{O}_{(\text {TEA })}$ bonds. However, the gradual drop of TCF values for both $\mathrm{O}_{-}$nbri-H@O $\mathrm{O}_{(\mathrm{TEA})}$ and Ca_interl- $\mathrm{O}_{\text {(TEA) }}$ bonds beyond a critical time indicates that the bonds become unstable with time elapsing (refer to Fig. 9a). Therefore, the intercalation of PAM molecules into $\mathrm{C}-\mathrm{S}-\mathrm{H}$ gel would offer a strong and stable bond with substrate, thus influencing the final mechanical propertie significantly.

It has been widely acknowledged that the mobility of water molecules in $\mathrm{C}-\mathrm{S}-\mathrm{H}$ gel is dependent on the impermeability of $\mathrm{C}-\mathrm{S}-\mathrm{H}$ gel, which can be further interpreted in terms of mean square displacement (MSD) as illustrated below 4,16 : 


$$
\operatorname{MSD}(t)=\left\langle r_{i}(t)-\left.r_{i}(0)\right|^{2}\right\rangle
$$

in which $r_{i}(0)$ is the initial position of atom $i$ and $r_{i}(\mathrm{t})$ is the current position of atom $i$ at time $t . \operatorname{MSD}(\mathrm{t})$ describes the deviation of atom $i$ from its original position after elapsed time $t$. As shown in Fig. 10a that MSD values of water molecules in C-S-H gel, TEPA / C-S-H gel, PAM / C-S-H gel and TEA / C-S-H gel are $1.33 \AA^{2}, 3.12 \AA^{2}, 8.57 \AA^{2}$ and $3.44 \AA^{2}$, respectively. It is obvious to realize that MSD value of water molecules in amine / $\mathrm{C}-\mathrm{S}-\mathrm{H}$ gel is greater than that in $\mathrm{C}-\mathrm{S}-\mathrm{H}$ gel due to the fact that the introduction of amine molecules releases the confined water molecules by $\mathrm{C}-\mathrm{S}-\mathrm{H}$ gel, thus leading to an increased mobility of water molecules. The highest MSD value (refer to Fig. 10a) implies the best mobility of water molecules in PAM / C-S-H gel than that in either TEPA / C-S-H gel or TEA / C-S-H gel, because PAM molecules enlarge the interlayer region most, offering much more space for water molecule diffusion. It can be observed from Fig. 10a that MSD values for TEPA / C-S-H gel and TEA / C-S-H gel are almost the same with time elapsing, indicating a similar size in the interlayer region. Besides, the interaction between amine molecules and water molecules also affected greatly the diffusion of water molecules. Averagely, each TEPA, PAM and TEA molecules could form 1.126, 0.714 and 1.291 hydrogen bonds with water molecules. PAM confined the least water molecules, but TEPA and TEA molecules bonded almost the same water molecules, contributing final results. It is known from Fig. 10b that mobility of amine molecules can be ranked as follows: PAM > TEA > TEPA, as PAM / C-S-H gel possesses the largest interlayer region and therein subsequent maximum mobility of PAM molecules. Compared with TEPA molecules, the smaller molecule size of TEA molecules represents a greater mobility, thus a poor stability. This instability of PAM or TEA molecules (refer to MSD curves in Fig. 10b) arises from the change of molecule conformation and rotation of branched structures in the space.

\subsection{Deformation and failure process of amine molecules / C-S-H gel under unixial loads}

To enable the application of materials in engineering, characterization of their mechanical properties is a must. In this section, uniaxial tensile load was applied to $\mathrm{C}-\mathrm{S}-\mathrm{H}$ gel, TEPA / C-S-H gel, PAM / C-S-H gel and TEA / C-S-H gel, respectively along $z$ direction (refer to Fig. 2). As stated in the review section, traditional investigations focused on mechanical properties of $\mathrm{C}-\mathrm{S}-\mathrm{H}$ gel with its interlayer region fully intercalated into organic molecules ${ }^{16}$, rather idealistic than realistic. Therefore, exploration of the mechanical properties of $\mathrm{C}-\mathrm{S}-\mathrm{H}$ gel with an unsaturated intercalation of organic molecules into its interlayer is necessary, but remaining chanllenging.

\subsubsection{Mechanical properties of amine molecules / C-S-H gel}

Figure 11 shows the stress-strain curves of $\mathrm{C}-\mathrm{S}-\mathrm{H}$ gel, TEPA / C-S-H gel, PAM / C-S-H gel and TEA / $\mathrm{C}-\mathrm{S}-\mathrm{H}$ gel, from which it can be seen that the profiles of all the curves are similar with an initial increase until a peak followed by a rapid stress drop. Note that yield strength here is defined as the maximum 
stress in the stress-strain curve ${ }^{41}$. Therefore, the yield strengths (refer to Fig. 11a) for C-S-H gel, TEPA / C-S-H gel, PAM / C-S-H gel and TEA / C-S-H gel are 2.76 GPa, 2.45 GPa, 1.67 GPa and 2.26 GPa, respectively. Though the nanocomposites seem to behave linearly at the beginning of deformation, Young's modulus (refer to Fig. 11b) demonstrates a strain softening nature, indicating a visco-elastic behavior. Compared with pure $\mathrm{C}-\mathrm{S}-\mathrm{H}$ gel, intercalation of TEPA molecules into the interlayer region of $\mathrm{C}-$ S-H gel decrease both of the yield strength and initial Young's modulus. This is due to the fact that TEPA molecules is rigid and could only bond one Ca-Si layer by forming hydrogen bonds with O_bri and O_nbri atoms, thus leaving a lower yield strength and initial Young's modulus.

Moreover, it can be seen from Fig. 11a that there is a gradual stress drop for the post-yielding behavior, implying that strain softening dominates such post-yielding deformation. However, the different amine molecule structures might lead to the change of the strain softening post-yield behavior. For example, the post-yield behavior for pure $\mathrm{C}-\mathrm{S}-\mathrm{H}$ gel can reach to a strain as high as $\sim 0.42$ ( $\varepsilon_{f}$ total failure / breakage of nanocomposites), the addition of amine molecules leads to a decrease of such value, implying an ease of bond breakage. The expansion of interlayer region is insignificant due to the linear and regular chain structure for TEPA molecule, which retains the structure of $\mathrm{C}-\mathrm{S}-\mathrm{H}$ gel, thus resulting in a minor decrease of stress-strain response. The post-yield behavior for TEPA can reach to a strain of $\sim 0.32$. However, the branched TEA and PAM molecules expand the interlayer region more seriously, giving rise to a lower mechanical response. As expected, the post-yield behavior for TEA / C-S-H gel can reach to a strain of $\sim 0.22$. The lower strain $\left(\varepsilon_{f}\right)$ means an easy breakage of bonds in the enlarged interlayer region.

Unlike TEA / C-S-H gel, it is interesting to observe that there is an insignificant decrease of such strain $\left(\varepsilon_{f}=\sim 0.36\right)$ for PAM / C-S-H gel compared with that for pure $\mathrm{C}-\mathrm{S}-\mathrm{H}$ gel. PAM molecules could bond simultaneously the both Ca-Si layer in the opposite directions by forming hydrogen bonds with O_bri and O_nbri atoms. The interaction between PAM molecule and calcium-silicate layer is so strong that leads to a local stress concentration in its neighbouring layer. Due to the unsaturatd intercalation of amine molecules into $\mathrm{C}-\mathrm{S}-\mathrm{H}$ gel, such adjacent layer is the pure $\mathrm{C}-\mathrm{S}-\mathrm{H}$ gel, which would domimate the postyield behavior of PAM / C-S-H gel. In other words, micro-crack initiates in $\mathrm{C}-\mathrm{S}-\mathrm{H}$ substrates rather than the interlayer region where PAM molecule intercaltes into. Since the local concentrated stress is high enough to break the chemical bond, making an early yielding of PAM / C-S-H gel. As breakage occurs in the substrates, the $\mathrm{C}-\mathrm{S}-\mathrm{H}$ gel will govern the post-yield behavior of PAM / $\mathrm{C}-\mathrm{S}-\mathrm{H}$ gel. Thus a slight reduce of failure strain compared with pure $\mathrm{C}-\mathrm{S}-\mathrm{H}$ gel results from the lower yield strength.

\subsubsection{Molecule interaction in amine molecules / C-S-H gel during uniaxial tension}

Molecule interaction plays an important role during deformation process. Except for bonding, the nonbond interaction $\left(E_{\text {total }}\right)$ consists of van der waals interaction $\left(E_{v a n}\right)$ and electrostatis interaction $\left(E_{e l e c}\right)$. As $E_{v a n}$ is much greater than $E_{e l e c}, E_{v a n}$ contributes more during tensile process. It can be seen from Fig. 12 that $E_{\text {total }}$ initially decreases with elongation of nanocomposites followed by a balance of

$E_{\text {total }}$ after strain exceeds $\sim 0.4$, indicating the failure of materials (refer to the corresponding stress-strain 
behavior in Fig. 11). However, minor oscillation of $E_{\text {total }}$ can be observed from Fig. 12 during uniaxial tensile process, implying the instable breakage of bonds due to the increased distance between atoms in the interlayer region. The initial decrease of $E_{\text {total }}$ mainly results from the desorption between amine molecules and $\mathrm{C}-\mathrm{S}-\mathrm{H}$ gel. As amine molecules contain a variety of atoms with distinguished polarity and property, the weak interaction tends to break earlier followed by the debonding of strong bonds. Therefore, the consumed $E_{\text {total }}$ would be the major part for energy absorption of nanocomposites.

Figure 13 gives the predicted deformation and failure process in $\mathrm{C}-\mathrm{S}-\mathrm{H}$ gel at different strain stages during the uniaxial tensile test. As can be seen from Fig. 13a that $\mathrm{C}-\mathrm{S}-\mathrm{H}$ gel deforms uniformly at the early loading stage. However, its initial elastic modulus is not constant (refer to Fig. 11b) due to the interaction between atoms, demonstrating a visco-elastic property. With the increase of the load to the peak stress (refer to Fig. 13b), the occurrence of breakage for both $\mathrm{Ca}-\mathrm{O}$ bonds and hydrogen bonds gives rise to the initiation of micro-crack. Further loads during the uniaxial tension cause the fast propagation of micro-crack (refer to Fig. 13c and Fig. 13d), thus resulting in the total failure of $\mathrm{C}-\mathrm{S}-\mathrm{H}$ gel.

With the intercalation of TEPA molecule with linear structure into $\mathrm{C}-\mathrm{S}-\mathrm{H}$ gel (refer to Fig. 14), the applied uniaxial tensile load to the nanocomposite enables the elongation of TEPA / C-S-H gel. Similar to the deformation of $\mathrm{C}-\mathrm{S}-\mathrm{H}$ gel at the early loading stage (refer to Fig. 14a), TEPA / C-S-H gel deforms viscoelastically. With further loading, the failure of bonds between $\mathrm{Ca}$ atoms, O_bri atoms and O_nbri atoms and $\mathrm{NH}$ groups of TEPA molecule promotes the initiation of micro-cracks. As the $\mathrm{NH}$ groups locate in the chain, high steric hindrance leads to a low bonding energy between $\mathrm{Ca}$ atoms and $\mathrm{N}$ atoms (refer to Fig. 14b). However, bonding energy between $\mathrm{Ca}$ atoms and $\mathrm{N}$ atoms in $\mathrm{NH}_{2}$ groups of TEPA is much greater, remaining linked at this moment. The possible reason is that the $\mathrm{NH}_{2}$ groups present at the ends of TEPA molecules, therein a smaller steric hindrance and subsequent stronger linkage with $\mathrm{Ca}$ atoms. As shown in Fig. 14c, Fig. 14d and Fig. 14e, Ca-N bonds remain intact with the increase of deformation. Since the intercalated TEPA molecules could only bond with one Ca-Si layer, but no interaction with the other layer, resulting in the weak interaction between both $\mathrm{Ca}$-Si layer. The intercalated interlayer regions are prone to break, implying a lower stress-strain response in TEPA / $\mathrm{C}-\mathrm{S}-\mathrm{H}$ gel.

Akin to TEPA / C-S-H gel, the intercalated TEA molecules into $\mathrm{C}-\mathrm{S}-\mathrm{H}$ gel demonstrates a similar deformation behavior as shown in Fig. 15. Nevertheless, different mechanism appears due to the branched molecule structures. As shown in Fig. 1c that $\mathrm{N}$ atoms locate in the center of the dendric TEA molecule structure with a high steric hindrance, resulting in the formation of no bonds between $\mathrm{N}$ atoms of TEA molecues and $\mathrm{C}-\mathrm{S}-\mathrm{H}$ substrates. However, the hydroxyl groups of TEA molecules could form bonds or hydrogen bonds with $\mathrm{Ca}$ atoms or Oxygen atoms of $\mathrm{C}-\mathrm{S}-\mathrm{H}$ gel. However, the intercalated TEA molecule into $\mathrm{C}-\mathrm{S}-\mathrm{H}$ gel could only bond with either of neighboring $\mathrm{Ca}-\mathrm{Si}$ layers due to the small steric size. Therefore, the initiation of micro-cracks is probably due to the appearance of broken Ca-O_nbri bonds or hydrogen bonds among $\mathrm{C}-\mathrm{S}-\mathrm{H}$ gel in TEA / $\mathrm{C}-\mathrm{S}-\mathrm{H}$ gel subjected to a uniaxial tensile load (refer to Fig. 15b). As the ends of TEA molecules contain hydroxyl groups with strong polarity and low 
steric hindrance, forming stable bonds with $\mathrm{C}-\mathrm{S}-\mathrm{H}$ gel, which is much stronger than the interaction between TEA molecules. Consequently, the weak interaction between TEA molecules might be another possible reason for micro-crack propagation, thus dominating the failure of TEA / $\mathrm{C}-\mathrm{S}-\mathrm{H}$ gel.

Unlike any of the aforementioned nanocomposites, the intercalation of PAM molecules into $\mathrm{C}-\mathrm{S}-\mathrm{H}$ gel shows a more interesting deformation behavior (refer to Fig. 16). Since PAM molecule is large to stretch across the interlayer region to bond with both of its neighboring Ca-Si layers together, the adhesive strength between PAM molecules and $\mathrm{C}-\mathrm{S}-\mathrm{H}$ gel are much stronger than any others (refer to Fig. $7 \mathrm{~b}$ ). Besides, the PAM molecules affect the atom arrangement of substrates more seriously, leading to a poor mechanical property. As can be seen from Fig. 16a and Fig. 16b that hydrogen bonds are broken with the accumulation of tensile strain. Though the local stress is high enough to break the hydrogen bonds in the substrates, it is insufficient to break the bonds between polar $\mathrm{NH}_{2}$ groups in PAM molecule and $\mathrm{Ca}$ atoms or Oxygen atoms in the $\mathrm{C}-\mathrm{S}-\mathrm{H}$ gel substrate with the strain increase. Therefore, micro-crack initiates from the interlayer region without PAM molecules as shown in Fig. 16c, Fig. 16d and Fig. 16e, implying that mechanical property of $\mathrm{C}-\mathrm{S}-\mathrm{H}$ gel dominates the failure process of PAM / C-S-H gel. In a word, the unsaturated intercalation of amine molecules into $\mathrm{C}-\mathrm{S}-\mathrm{H}$ gel would significantly influence the mechanical property of the as-generated nanocomposites. Local stress concentration occurs in other interlayer region in spite of the formation of stronger bonds between PAM molecules and $\mathrm{C}-\mathrm{S}-\mathrm{H}$ gel, thus leading to a drop of mechanical properties.

\section{Conclusions}

The unsaturated intercalation of amine molecules into $\mathrm{C}-\mathrm{S}-\mathrm{H}$ gel were numerically investigated via molecular dynamics simulation. Effect of amine molecule strucutres on the characteristics of nanocomposites was performed followed by the investigation of deformation and failure analysis of nanocomposites subjected to uniaxial tensile loads. The main conclusions were drawn as follows.

- Unsaturated intercalation of amine molecules into $\mathrm{C}-\mathrm{S}-\mathrm{H}$ gel plays a key role in the geometry and subsequent density of nanocomposites. The interaction of polar amine functional groups in TEPA molecules with the opposite $\mathrm{Ca}-\mathrm{Si}$ layer in the substrates leads to a shrinkage of geometric volume and subsequent an increase of density. However, branched TEA and PAM molecules expands the geometric volume seriously, therein a decrease of material's density.

- Penetration of $\mathrm{O}$ atoms of amine molecules into the $\mathrm{Ca}-\mathrm{Si}$ layer results in a strong interaction between amine molecules and $\mathrm{C}-\mathrm{S}-\mathrm{H}$ gel. Even amine molecules intercalate into the interlayer region, bond length in $\mathrm{Ca}-\mathrm{Si}$ layer and interaction between $\mathrm{Ca}-\mathrm{Si}$ layer and water molecules remain unchanged. However, the change of coordination number means the rearrangement of $\mathrm{Ca}-\mathrm{Si}$ layer.

- The interaction between amine molecules with $\mathrm{Ca}-\mathrm{Si}$ layer takes place through $\mathrm{N}$ atoms for TEPA molecules, $\mathrm{N}, \mathrm{O}$ and active $\mathrm{H}$ atoms for PAM molecules, and $\mathrm{O}$ and active $\mathrm{H}$ atoms for TEA molecules. It is noteworthy that formation of hydrogen bonds occurs between water molecules, C$\mathrm{S}-\mathrm{H}$ gel substrates and amine molecules. Meanwhile, introduction of amine molecules in the 
interlayer region accelerates water diffusion due to the enlarged spacing between interlayer regions and weak bonding interactions between amine molecules and water molecules.

- Molecular dynamics predictions reveal that deformation and failure process depends on the unsaturated intercalation of amine molecules into $\mathrm{C}-\mathrm{S}-\mathrm{H}$ gel, thus offering different mechanisms. The occurrence of breakage of $\mathrm{Ca}-\mathrm{O}$ bonds and hydrogen bonds dominates the failure of $\mathrm{C}-\mathrm{S}-\mathrm{H}$ gel. Rigid TEPA molecule and small TEA molecules could not interact simultaneously with both Ca-Si layer, leading to a reduction of material's strength. However, PAM molecules with large size and soft properties bonded simultaneously the Ca-Si layer together, bringing local stress concentration in other interlayer region without PAM molecules, governing the uniaxial tensile deformation and fracture process.

\section{Declarations}

\section{Ethics approval and consent to participate}

Not applicable

\section{Adherence to national and international regulations}

Not applicable

\section{Consent for publication}

Not applicable

\section{Availability of data and material}

The datasets used or analyzed during the current study are available from the corresponding author on reasonable request.

\section{Competing interests}

The authors declare that they have no competing interests.

\section{Funding}

The authors gratefully acknowledge the financial support of the National Natural Science Foundation of China (52002006 and 11802028) and General Program of Science and Technology Development Project of Beijing Municipal Education Commission (KM202010005004).

\section{Authors' contributions}

Dawei Sun: Methodology, Investigation, Writing - original draft, Writing - review \& editing. Zheng Yan: Project administration, Formal analysis. Jianhua Yan: Project administration, Formal analysis. Yali 
Wang: Supervision, Formal analysis. Jianfeng Wang: Project administration, Formal analysis. Lan Mingzhang: Supervision, Formal analysis. Wang Ziming: Supervision, Formal analysis. Zherui Chen: project administration, Formal analysis. Cui Suping: Resources, Supervision, Formal analysis, Funding acquisition, Writing - review \& editing. Zhiyong Wang: Conceptualization, Resources, Formal analysis, Funding acquisition.

\section{Acknowledgements}

The authors also acknowledge the National Supercomputing Center in Shenzhen for providing computational resources and Key Laboratory of Advanced Functional Materials, Education Ministry of China.

\section{Data availability}

The raw/processed data required to reproduce these findings cannot be shared at this time as the data also forms part of an ongoing study.

\section{References}

1. Han SH, Park WS, Yang El (2013) Evaluation of concrete durability due to carbonation in harbor concrete structures. Constr Build Mater 48:1045-1049. DOI:10.1016/j.conbuildmat.2013.07.057

2. Vilardell J, Aguado A, Agullo L, Gettu R (1998) Estimation of the modulus of elasticity for dam concrete. Cem Concr Res 28(1):93-101. DOI:10.1016/s0008-8846(97)00214-7

3. Jung Y, Lin W, Hao H, Cho Y-H (2017) Interface behavior of partial depth repair for airport concrete pavement subjected to differential volume change. Constr Build Mater 143:515-521.

DOI:10.1016/j.conbuildmat.2017.03.161

4. Sun D, Wang Y, Ma W, Lan M, Wang Z, Sun S, Tian Y, Guo H, Chen Z, Cui S, Wang Z C - S-H gel structure and water molecules behaviors under different chemical environments in a range of temperatures. Materials Today Communications 2020, 101866, DOl:https://doi.org/10.1016/j.mtcomm.2020.101866

5. Allen AJ, Thomas JJ, Jennings HM (2007) Composition and density of nanoscale calcium-silicatehydrate in cement. Nat Mater 6(4):311-316. DOI:10.1038/nmat1871

6. Hou DS, Ma HY, Yu Z, Li ZJ (2014) Calcium silicate hydrate from dry to saturated state: Structure, dynamics and mechanical properties. Acta Mater 67:81-94. DOI:10.1016/j.actamat.2013.12.016

7. Ha J, Chae S, Chou KW, Tyliszczak T, Monteiro PJM (2012) Effect of polymers on the nanostructure and on the carbonation of calcium silicate hydrates: a scanning transmission X-ray microscopy study. J Mater Sci 47(2):976-989. DOI:10.1007/s10853-011-5877-x

8. Lee BY, Kim J-K, Kim J-S, Kim YY. Quantitative evaluation technique of Polyvinyl Alcohol (PVA) fiber dispersion in engineered cementitious composites. Cement and Concrete Composites 2009, 31 (6), 408-417 
9. Li CZ, Feng NQ, Li YD, Chen RJ Effects of polyethlene oxide chains on the performance of polycarboxylate-type water-reducers. Cement and Concrete Research 2005, 35 (5), 867-873, DOI: 10.1016/j.cemconres.2004.04.031

10. Yang XJ, Liu JS, Li HX, Xu LL, Ren Q, Li L (2019) Effect of triethanolamine hydrochloride on the performance of cement paste. Constr Build Mater 200:218-225.

DOI:10.1016/j.conbuildmat.2018.12.124

11. Young JF (1972) A review of the mechanisms of set-retardation in portland cement pastes containing organic admixtures. Cem Concr Res 2(4):415-433. DOl:https://doi.org/10.1016/00088846(72)90057-9

12. Beaudoin JJ, Patarachao B, Raki L, Alizadeh R (2009) The interaction of methylene blue dye with calcium-silicate-hydrate. J Am Ceram Soc 92(1):204-208. DOI:10.1111/j.1551-2916.2008.02839.x

13. Beaudoin JJ, Patarachao B, Raki L, Alizadeh R The interaction of methylene blue dye with calciumsilicate-hydrate. Journal of the American Ceramic Society 2009, 92 (1), 204-208

14. Matsuyama H, Young JF (1999) Intercalation of polymers in calcium silicate hydrate: A new synthetic approach to biocomposites? Chem Mat 11(1):16-16+. DOI:10.1021/cm980549|

15. Pellenq RJM, Lequeux N, van Damme H (2008) Engineering the bonding scheme in C-S-H: The ionocovalent framework. Cem Concr Res 38(2):159-174. DOI:10.1016/j.cemconres.2007.09.026

16. Hou DS, Yu J, Wang P (2019) Molecular dynamics modeling of the structure, dynamics, energetics and mechanical properties of cement-polymer nanocomposite. Compos Pt B-Eng 162:433-444. DOI:10.1016/j.compositesb.2018.12.142

17. Minet J, Abramson S, Bresson B, Franceschini A, Van Damme H, Lequeux N (2006) Organic calcium silicate hydrate hybrids: a new approach to cement based nanocomposites. J Mater Chem 16(14):1379-1383. DOI:10.1039/b515947d

18. Zhou Y, Hou DS, Jiang JY, She W, Li JQ (2017) Molecular dynamics study of solvated aniline and ethylene glycol monomers confined in calcium silicate nanochannels: a case study of tobermorite. Phys Chem Chem Phys 19(23):15145-15159. DOI:10.1039/c7cp02928d

19. Zhou Y, Hou DS, Jiang JY, Wang PG (2016) Chloride ions transport and adsorption in the nano-pores of silicate calcium hydrate: Experimental and molecular dynamics studies. Constr Build Mater 126:991-1001. DOI:10.1016/j.conbuildmat.2016.09.110

20. Bessaies-Bey H, Baumann R, Schmitz M, Radler M, Roussel N Effect of polyacrylamide on rheology of fresh cement pastes. Cement and Concrete Research 2015, 76, 98-106, DOI:

10.1016/j.cemconres.2015.05.012

21. Rai US, Singh RK (2005) Effect of polyacrylamide on the different properties of cement and mortar. Materials Science Engineering A-Structural Materials Properties Microstructure Processing 392(12):42-50. DOI:10.1016/j.msea.2004.08.050

22. Hou DS, Li ZJ (2014) Molecular dynamics study of water and ions transported during the nanopore calcium silicate phase: Case study of Jennite. J Mater Civ Eng 26(5):930-940.

DOI:10.1061/(asce)mt.1943-5533.0000886

Page 19/37 
23. Roussel N, Bessaies-Bey H, Kawashima S, Marchon D, Vasilic K, Wolfs R Recent advances on yield stress and elasticity of fresh cement-based materials. Cem Concr Res 2019, 124, 11, DOI:10.1016/j.cemconres.2019.105798

24. Ramli M, Tabassi AA (2012) Effects of polymer modification on the permeability of cement mortars under different curing conditions: A correlational study that includes pore distributions, water absorption and compressive strength. Constr Build Mater 28(1):561-570.

DOI:10.1016/j.conbuildmat.2011.09.004

25. Khoshnazar R, Beaudoin JJ, Raki L, Alizadeh R Characteristics and engineering performance of C-SH/aminobenzoic acid composite systems. J. Adv. Concr. Technol. 2015, 13 (9), 415-420, DOI: $10.3151 /$ jact. 13.415

26. Matsuyama $\mathrm{H}$, Young JF Intercalation of polymers in calcium silicate hydrate: a new synthetic approach to biocomposites? Chemistry of materials 1999, 11 (1), 16-19

27. Minet J, Abramson S, Bresson B, Sanchez C, Montouillout V, Lequeux N (2004) New layered calcium organosilicate hybrids with covalently linked organic functionalities. Chem Mat 16(20):3955-3962. DOI:10.1021/cm034967o

28. Murray SJ, Subramani VJ, Selvam RP, Hall KD. Molecular dynamics to understand the mechanical behavior of cement paste. Transp Res Record 2010, (2142), 75-82, DOI:10.3141/2142-11

29. Khoshnazar R, Beaudoin JJ, Raki L, Alizadeh R (2014) Volume stability of calcium-silicatehydrate/polyaniline nanocomposites in aqueous salt solutions. ACI Mater J 111(6):623-632

30. Khoshnazar R, Alizadeh R, Beaudoin JJ, Raki L (2015) The physico-mechanical stability of C-SH/polyaniline nanocomposites. Mater Struct 48(1-2):67-75. DOI:10.1617/s11527-013-0168-4

31. Picker A, Nicoleau L, Burghard Z, Bill J, Zlotnikov I, Labbez C, Nonat A, Colfen H Mesocrystalline calcium silicate hydrate: A bioinspired route toward elastic concrete materials. Sci Adv 2017, 3 (11), 6, DOI:10.1126/sciadv.1701216

32. Honorio T Monte-Carlo molecular modeling of temperature and pressure effects on the interactions between crystalline calcium silicate hydrate layers. Langmuir 2019, 35 (11), 3907-3916, DOI: 10.1021/acs.langmuir.8b04156

33. Dong BQ, Fang GH, Ding WJ, Liu YQ, Zhang JC, Han NX, Xing F (2016) Self-healing features in cementitious material with urea-formaldehyde/epoxy microcapsules. Constr Build Mater 106:608617. DOI:10.1016/j.conbuildmat.2015.12.140

34. Shill SK, Al-Deen S, Ashraf M, Hutchison W, Hossain MM Performance of amine cured epoxy and silica fume modified cement mortar under military airbase operating conditions. Constr Build Mater 2020, 232, 12, DOI:10.1016/j.conbuildmat.2019.117280

35. Moshiri A, Stefaniuk D, Smith SK, Morshedifard A, Rodrigues DF, Qomi MJA, Krakowiak KJ Structure and morphology of calcium-silicate-hydrates cross-linked with dipodal organosilanes. Cem Concr Res 2020, 133, 12, DOI:10.1016/j.cemconres.2020.106076

36. Nakamura J, Suzuki Y, Narukawa R, Sugawara-Narutaki A, Ohtsuki C Preparation of layered calcium silicate organically modified with two types of functional groups for varying chemical stability. 
Journal of Asian Ceramic Societies 2021, DOI: 10.1080/21870764.2020.1854925

37. Hamid SA. The crystal structure of the $11 \AA ̊$ natural tobermorite Ca2.25[Si3O7.5(OH)1.5] $1 \mathrm{H} 2 \mathrm{O}$. Zeitschrift Für Kristallographie Crystalline Materials 1981

38. Sawamura T, Okuyama M, Maeda H, Obata A, Kasuga T (2016) Preparation of calcium-phosphate cements with high compressive strength using meglumine as a water reducer. J Ceram Soc Jpn 124(3):223-228. DOI:10.2109/jcersj2.15249

39. Masoumi S, Zare S, Valipour H, Qomi MJA Effective Interactions between Calcium-Silicate-Hydrate Nanolayers. J. Phys. Chem. C 2019, 123 (8), 4755-4766, DOI: 10.1021/acs.jpcc.8b08146

40. Land G, Stephan D (2018) The effect of synthesis conditions on the efficiency of C-S-H seeds to accelerate cement hydration. Cem Concr Compos 87:73-78.

DOI:10.1016/j.cemconcomp.2017.12.006

41. Wang ZY, Li PF (2020) Visco-elasto-plastic constitutive model of adhesives under uniaxial compression in a range of strain rates. J Appl Polym Sci 137(33):8. DOI:10.1002/app.48962

\section{Figures}


(a)

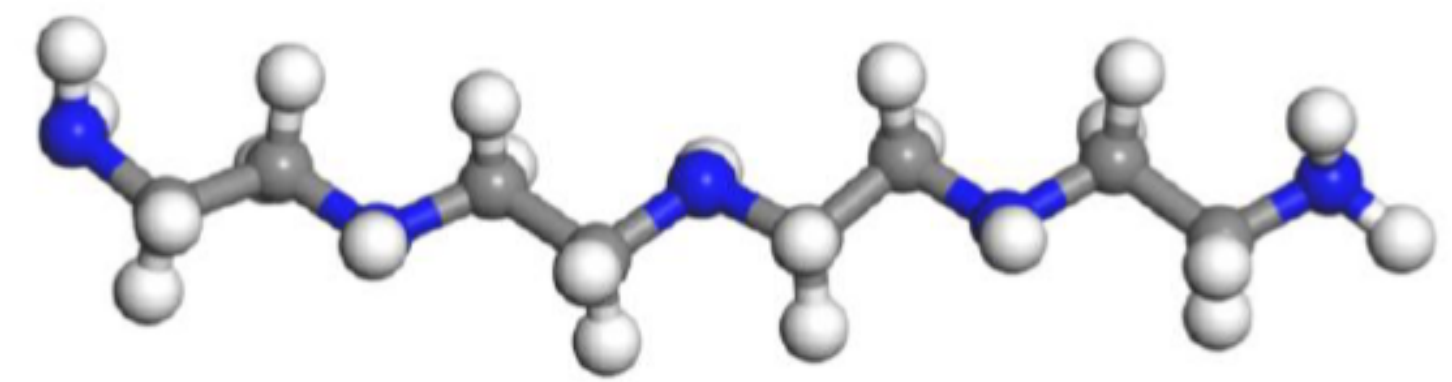

(b)
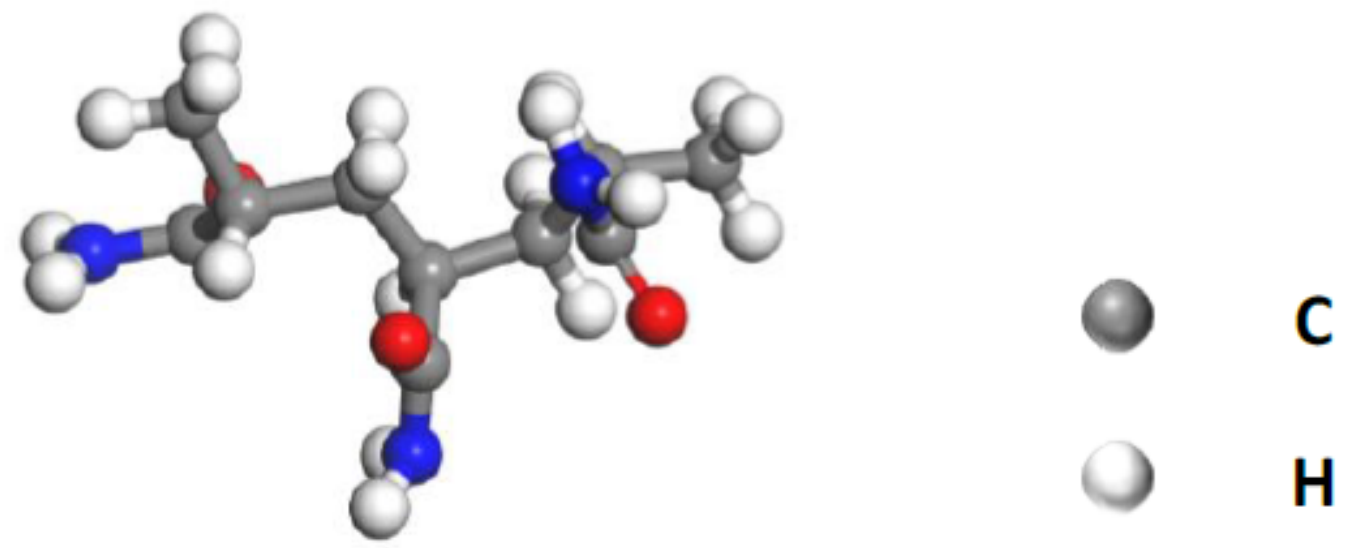

(c)
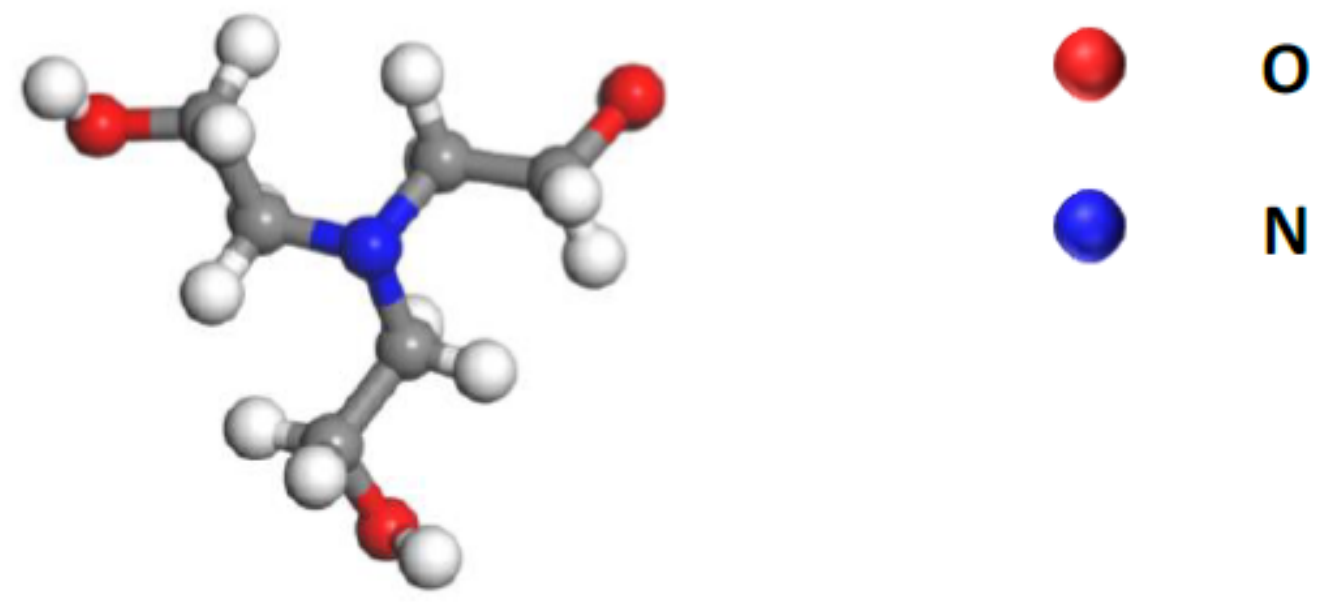

Figure 1

Structures of amine molecules: (a) Linear TEPA molecule, (b) PAM molecule and (c) TEA molecule. 

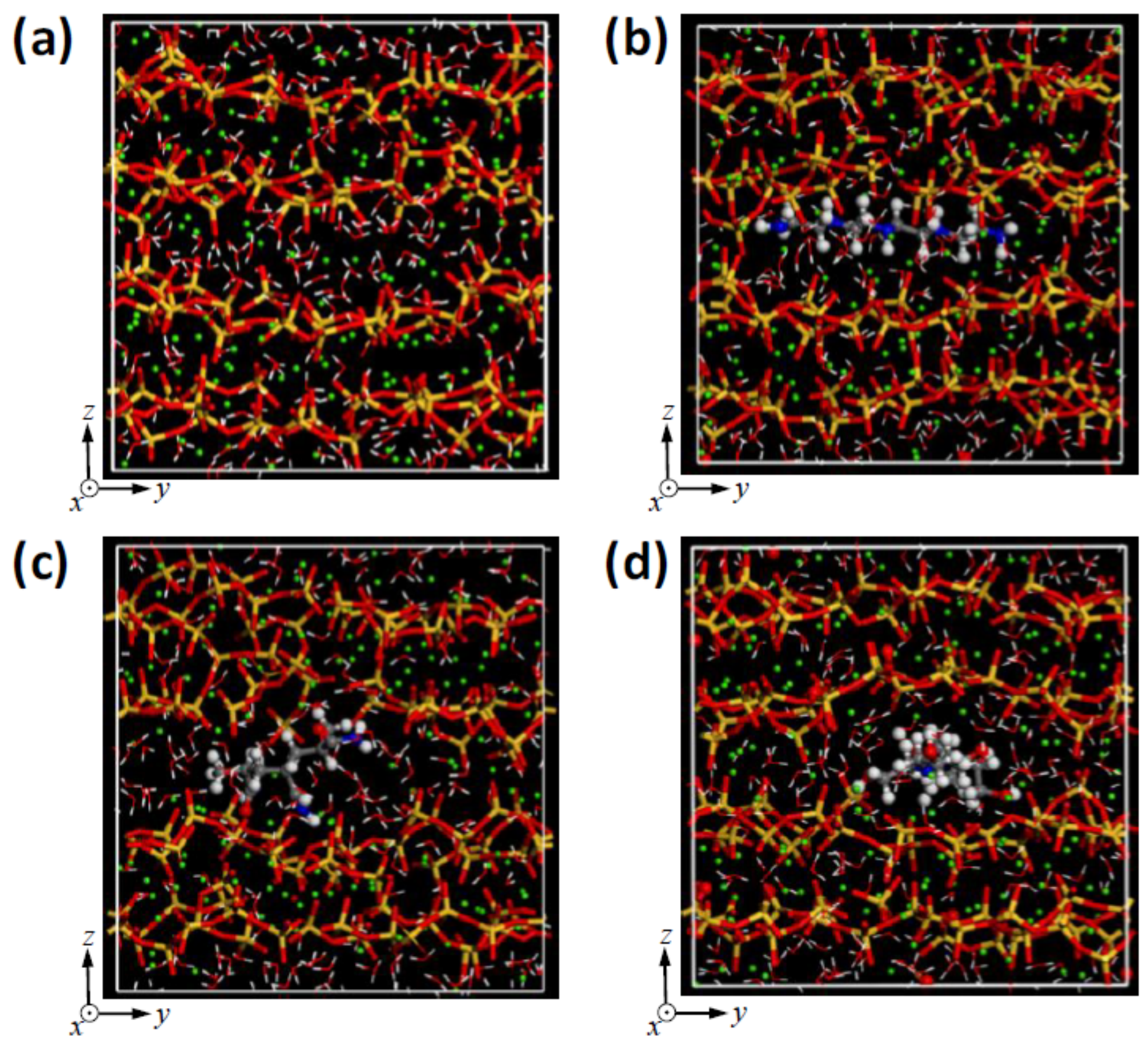

Figure 2

Representative molecular structures: (a) C-S-H gel, (b) TEPA / C-S-H gel, (c) PAM / C-S-H gel and (d) TEA / C-S-H gel. Note that yellow-red bonds are silicate-oxygen bonds, and red-white bonds are oxygenhydrogen bonds. The balls in green, white, grey, blue and red represent the atoms of calcium, hydrogen, carbon, nitrogen and oxygen, respectively. 

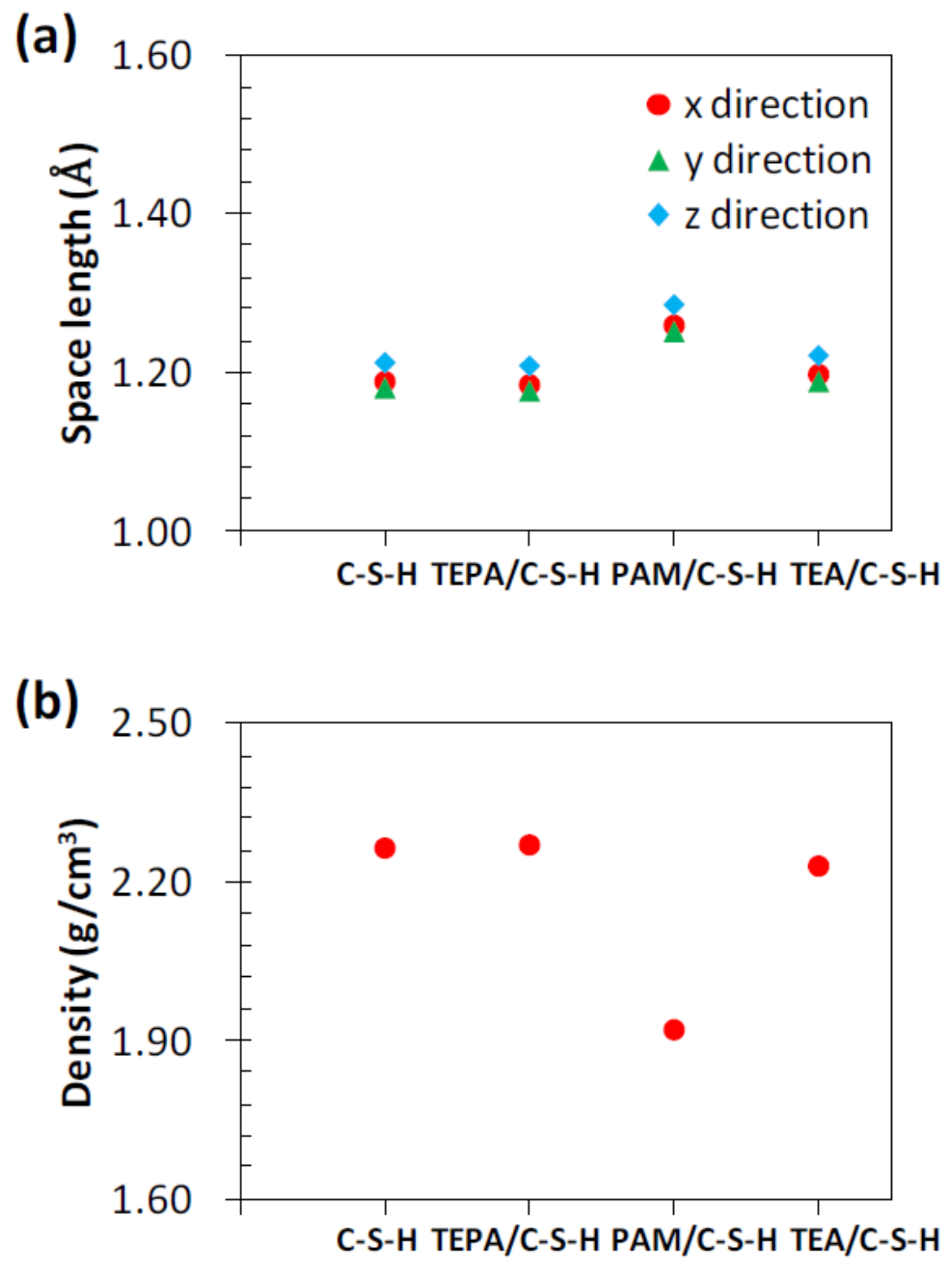

Figure 3

Effect of amine molecules on (a) Space length and (b) Density. 
(a)

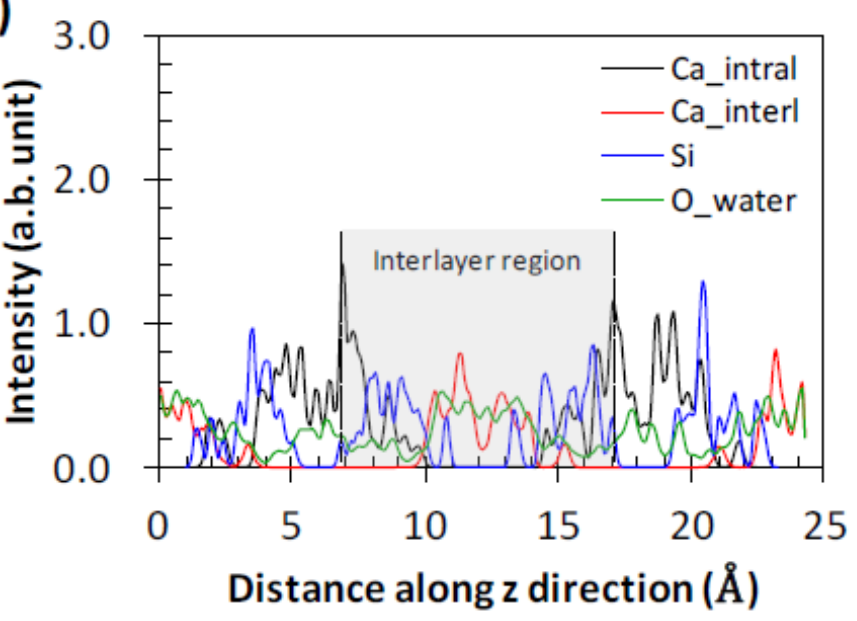

(c)

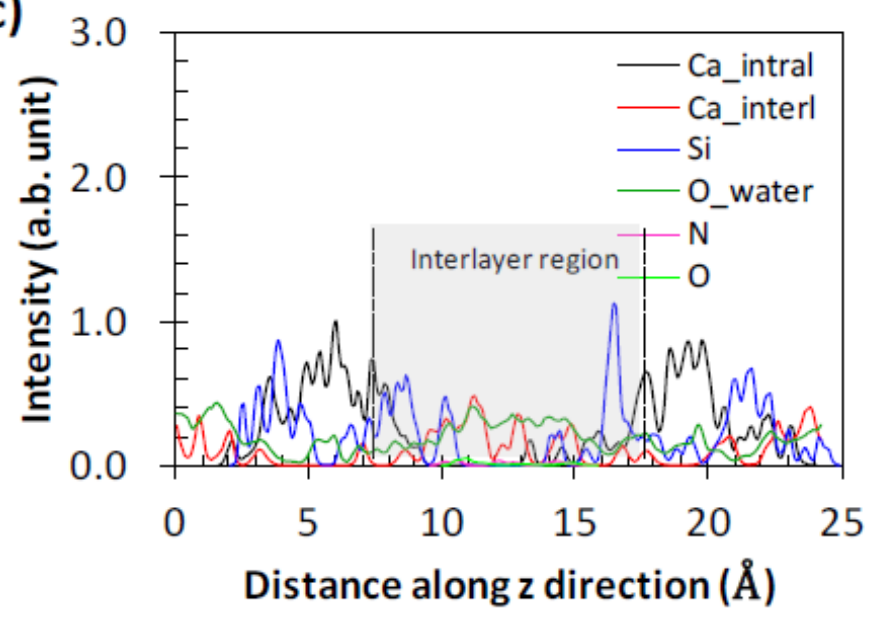

(b)

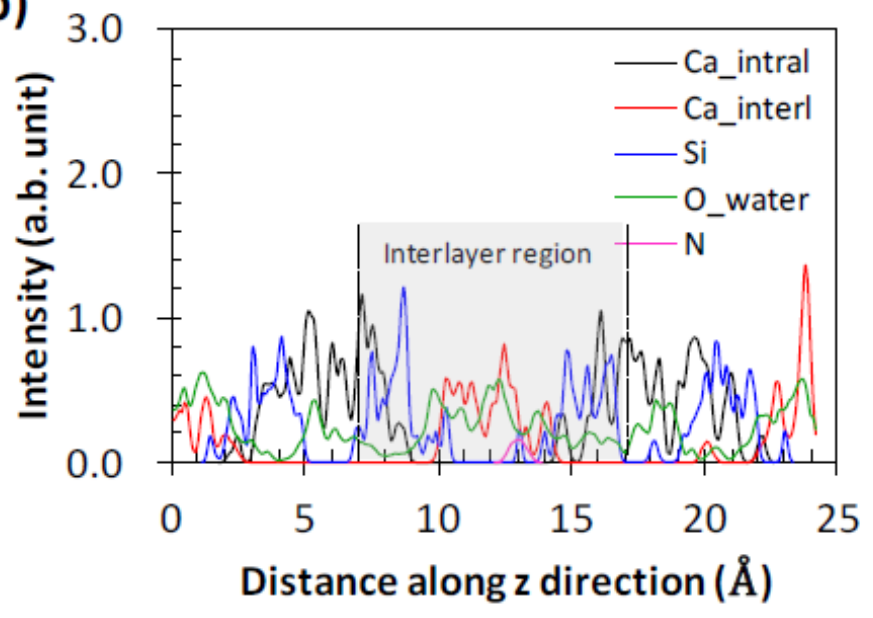

(d)

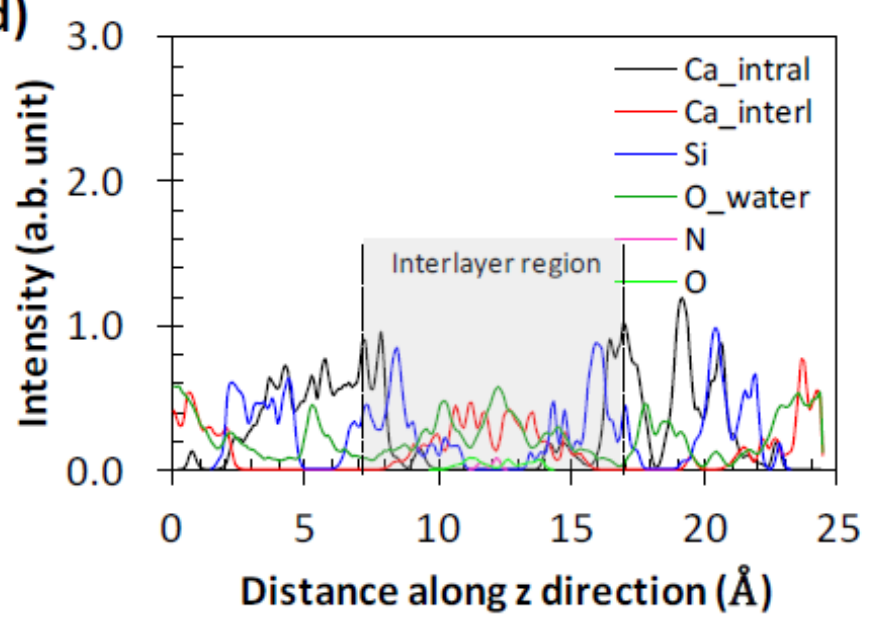

Figure 4

Density distribution along z direction of Ca_intral, Ca_interl, Si and O_water atoms in (a) $\mathrm{C}-\mathrm{S}-\mathrm{H}$ gel; Ca_intral, Ca_interl, Si, N and O_water atoms in (b) TEPA / C-S-H gel; Ca_intral, Ca_interl, Si, N, O and O_water in (c) PAM / C-S-H gel and (d) TEA / C-S-H gel. 
(a)

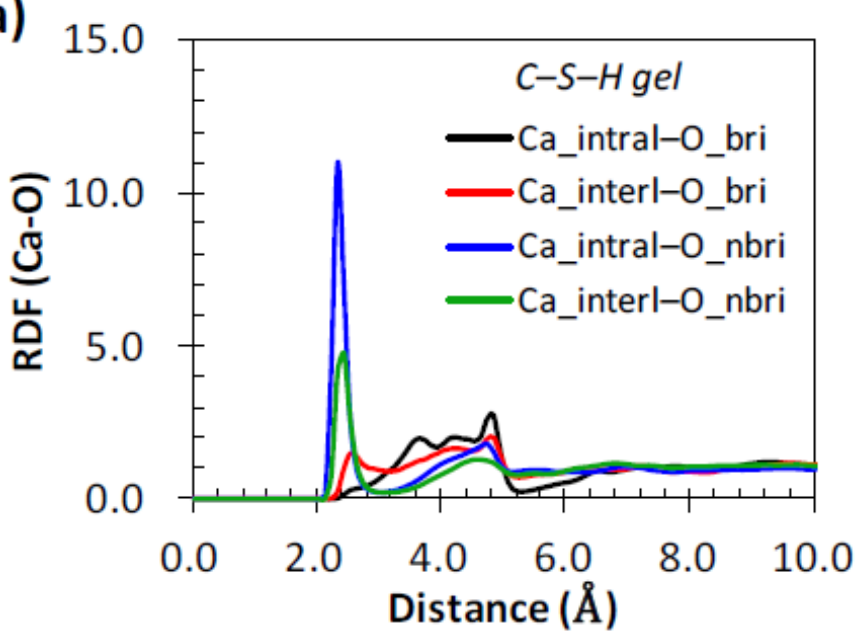

(c)

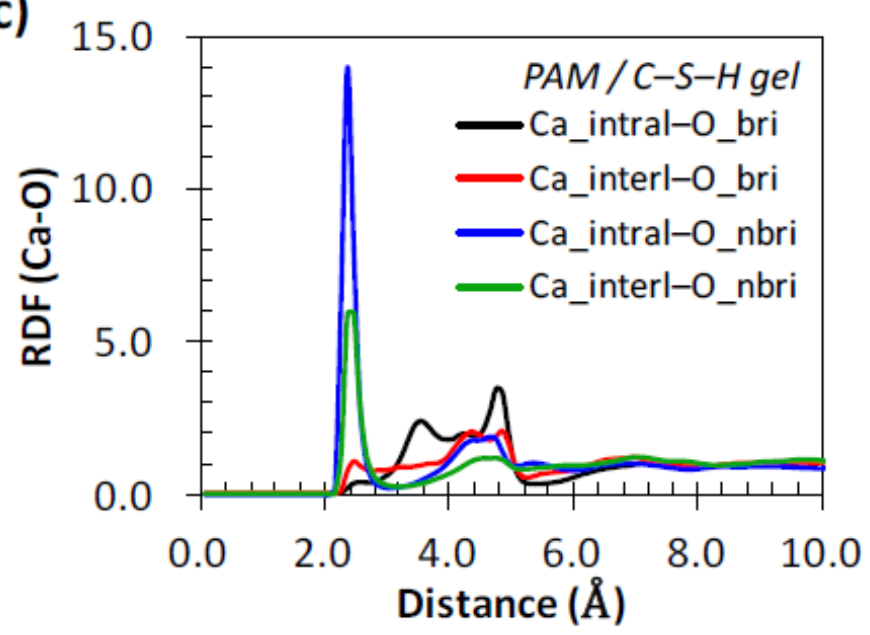

(b)

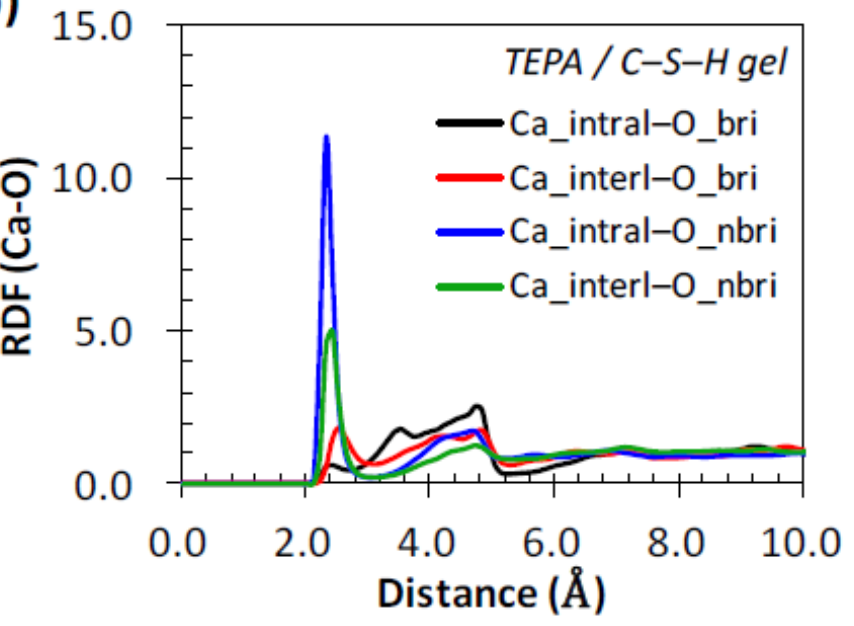

(d)

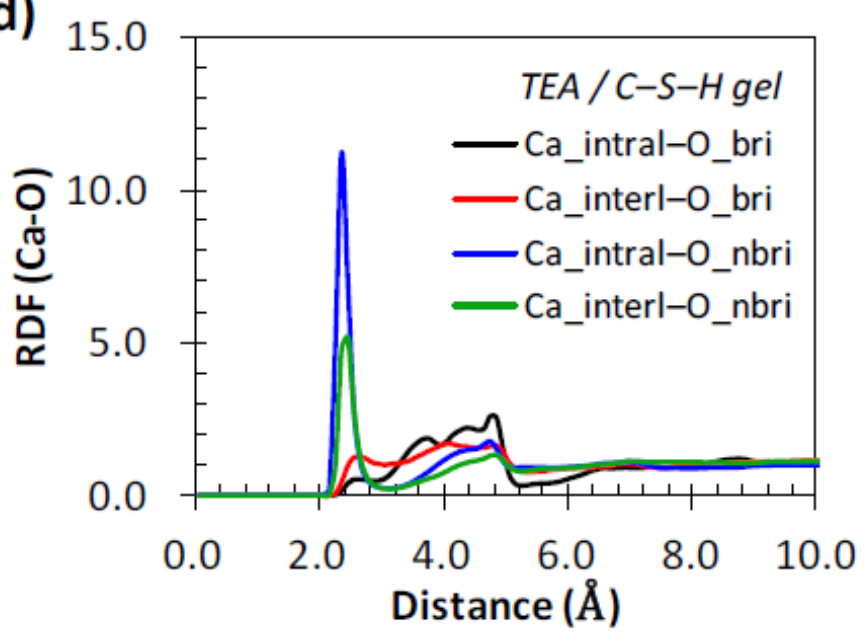

Figure 5

Interaction between $\mathrm{Ca}$ atoms and $\mathrm{O}$ atoms in nanocomposites: (a) $\mathrm{C}-\mathrm{S}-\mathrm{H}$ gel, (b) TEPA / C-S-H gel, (c) PAM / C-S-H gel and (d) TEA / C-S-H gel. 
(a)

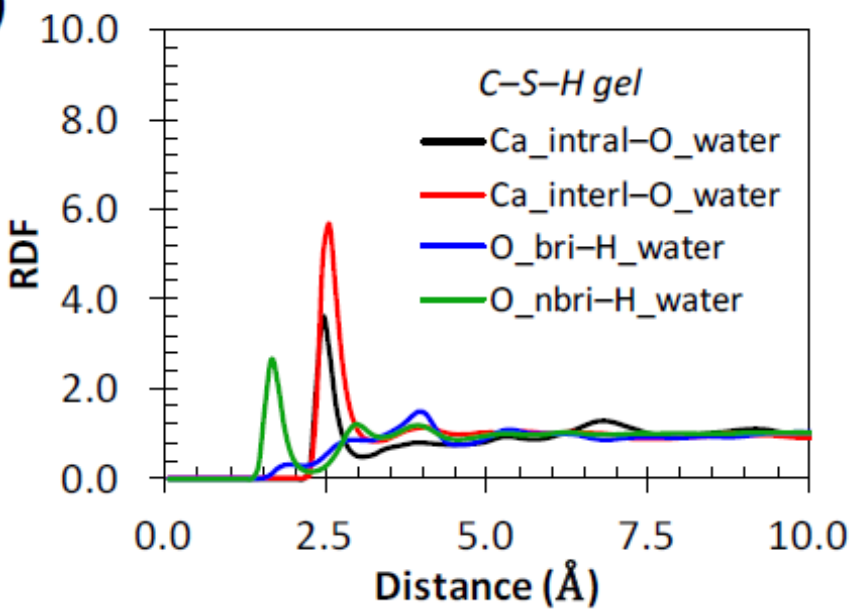

(c)

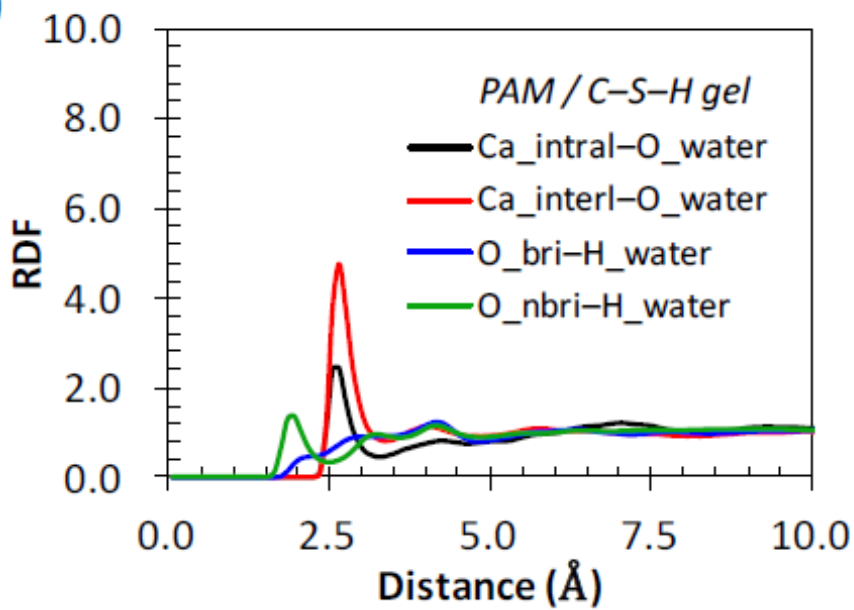

(b)

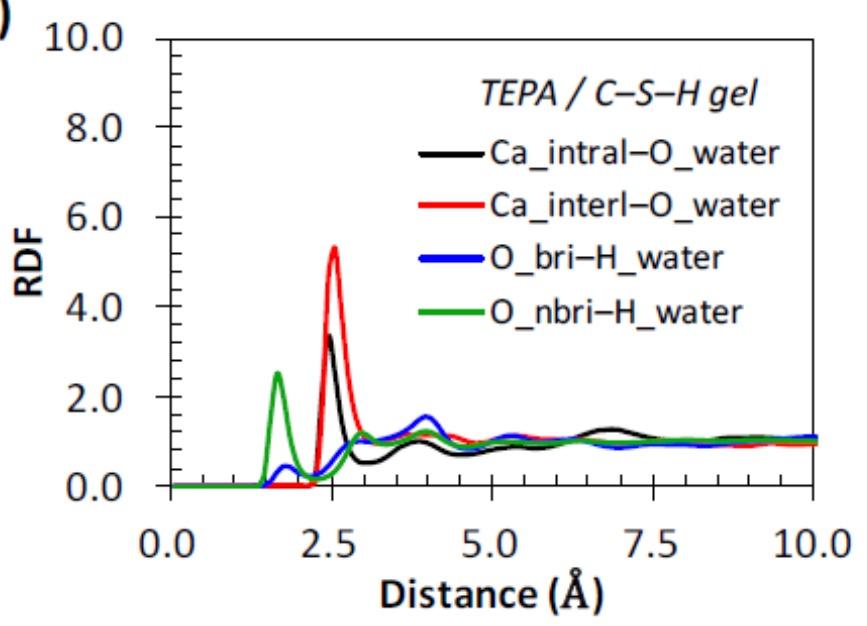

(d)

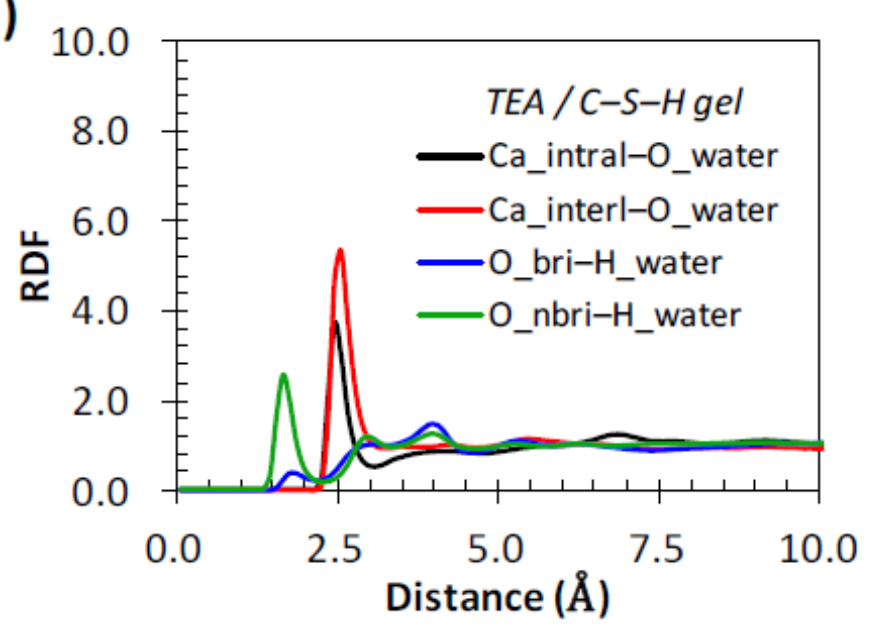

Figure 6

RDF curves of Ca_intral-O_water, Ca_interl-O_water, O_bri-H_water and O_nbri-H_water in: (a) C-S-H gel, (b) TEPA / C-S-H gel, (c) PAM / C-S-H gel and (d) TEA / C-S-H gel. 
(a)

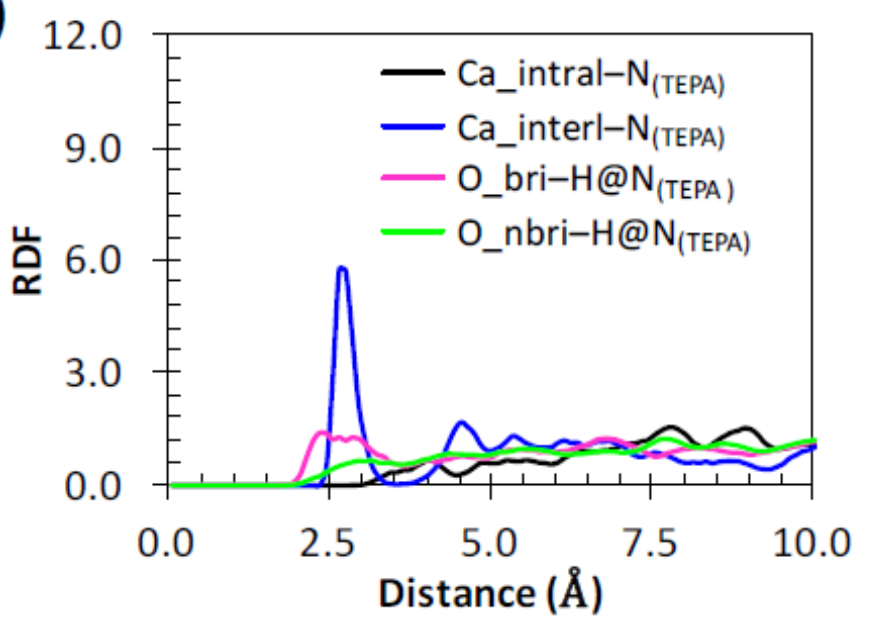

(c)

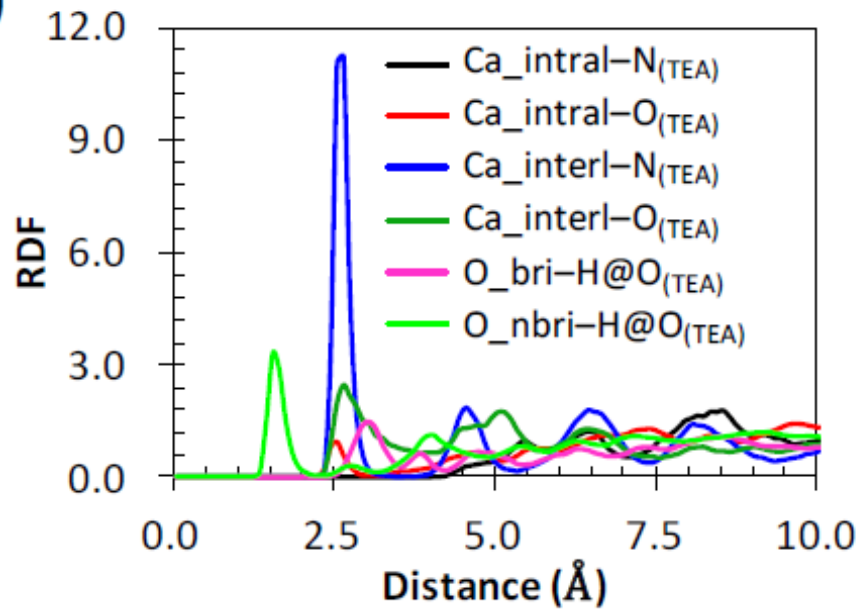

(b)

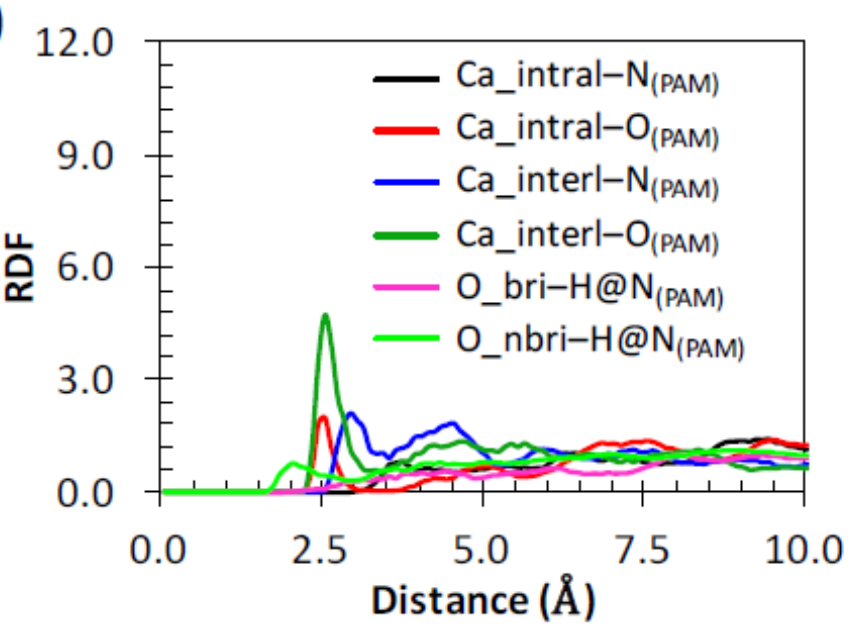

Figure 7

RDF curves of interaction pairs between amine molecules and atoms for $\mathrm{Ca}$ and $\mathrm{O}$ in (a) TEPA / $\mathrm{C}-\mathrm{S}-\mathrm{H}$ gel, (b) PAM / C-S-H gel and (c) TEA / C-S-H gel. 
(a)

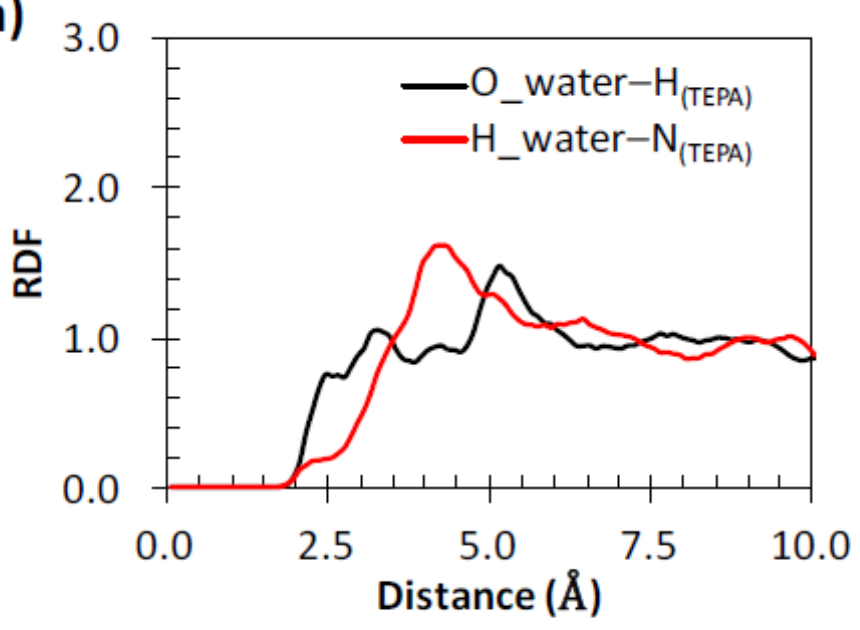

(c)

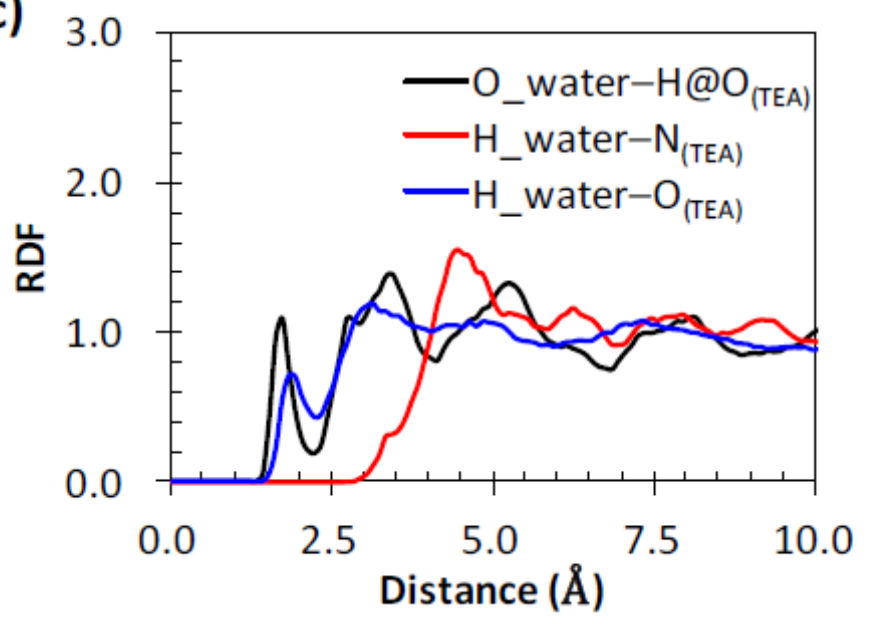

(b)

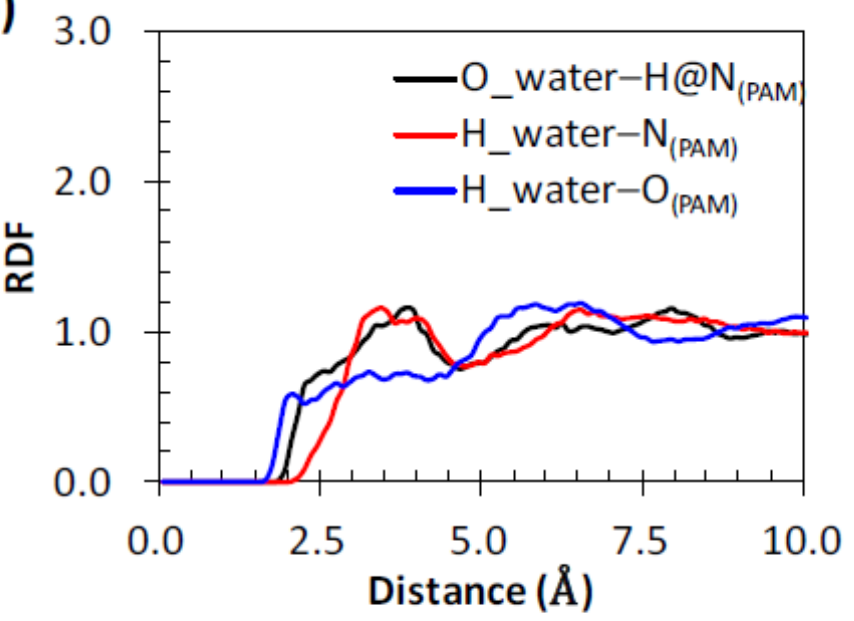

Figure 8

RDF curves of interaction pairs between amine molecules and water molecules in (a) TEPA / C-S-H gel, (b) PAM / C-S-H gel and (c) TEA / C-S-H gel. 
(a)
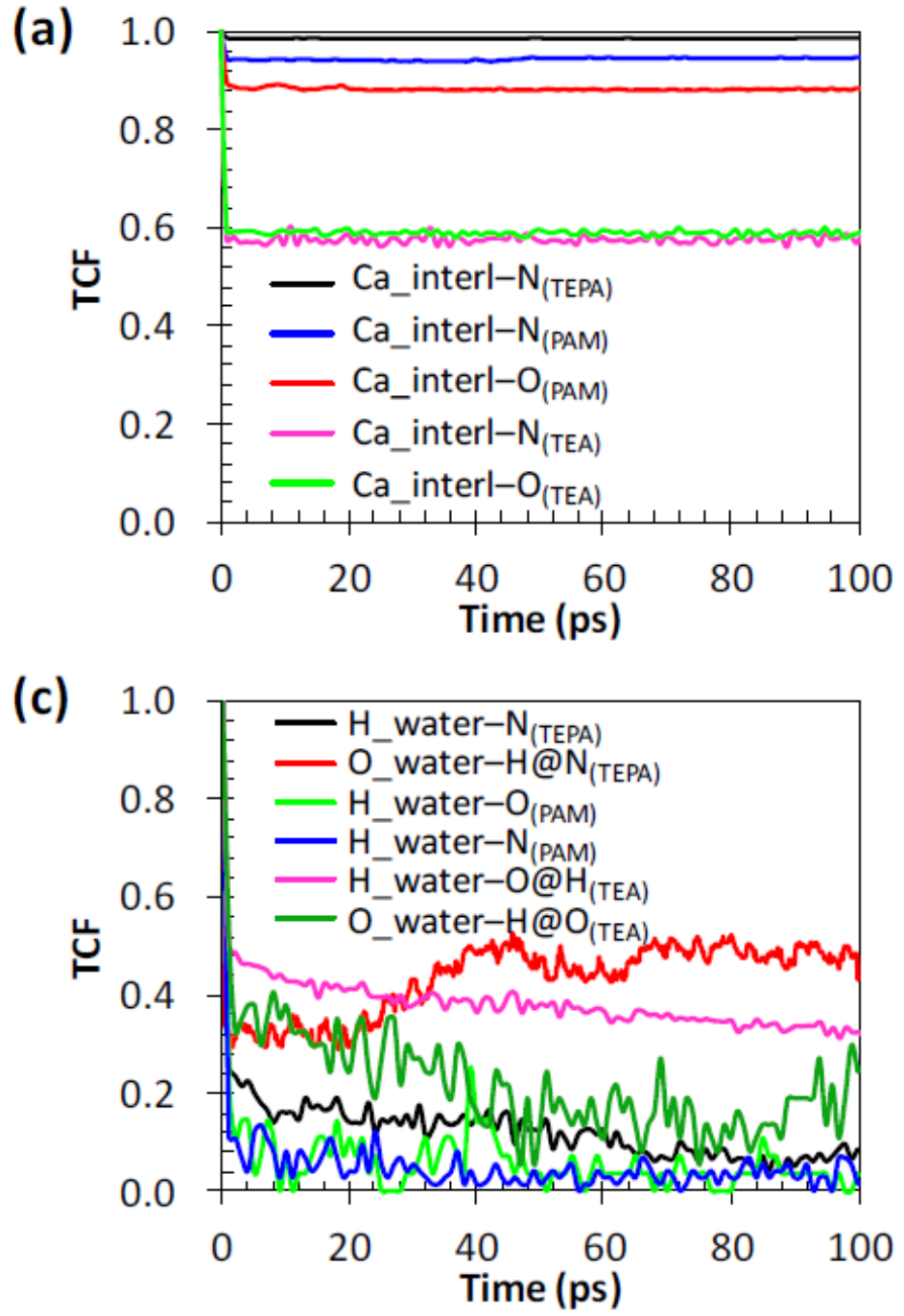

(b)

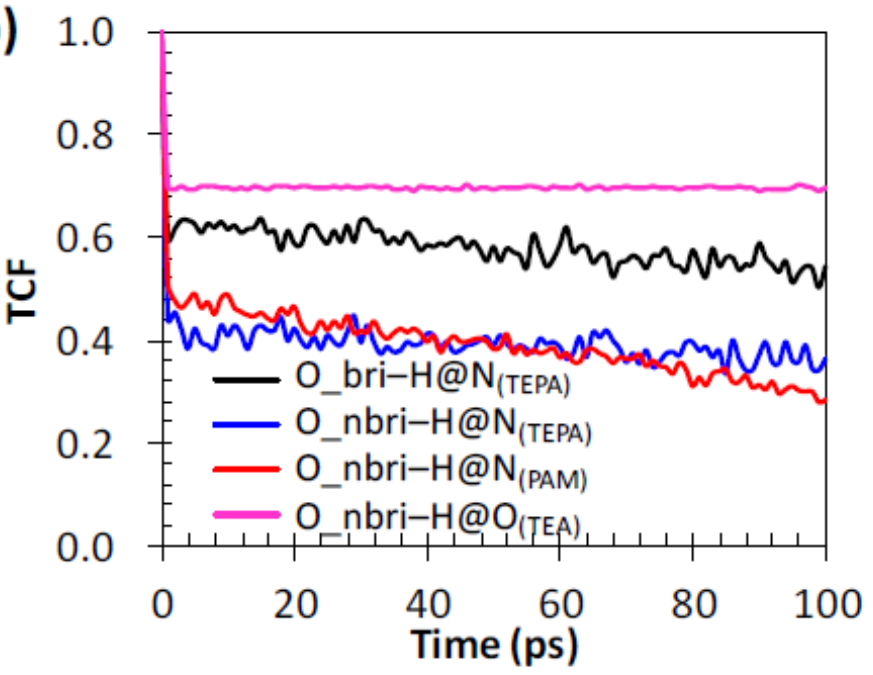

Figure 9

Time correlated function of bonds between amine molecules and (a) $\mathrm{C}-\mathrm{S}-\mathrm{H}$ gel, (b) $\mathrm{O}$ atoms, and (c) Water molecules. 

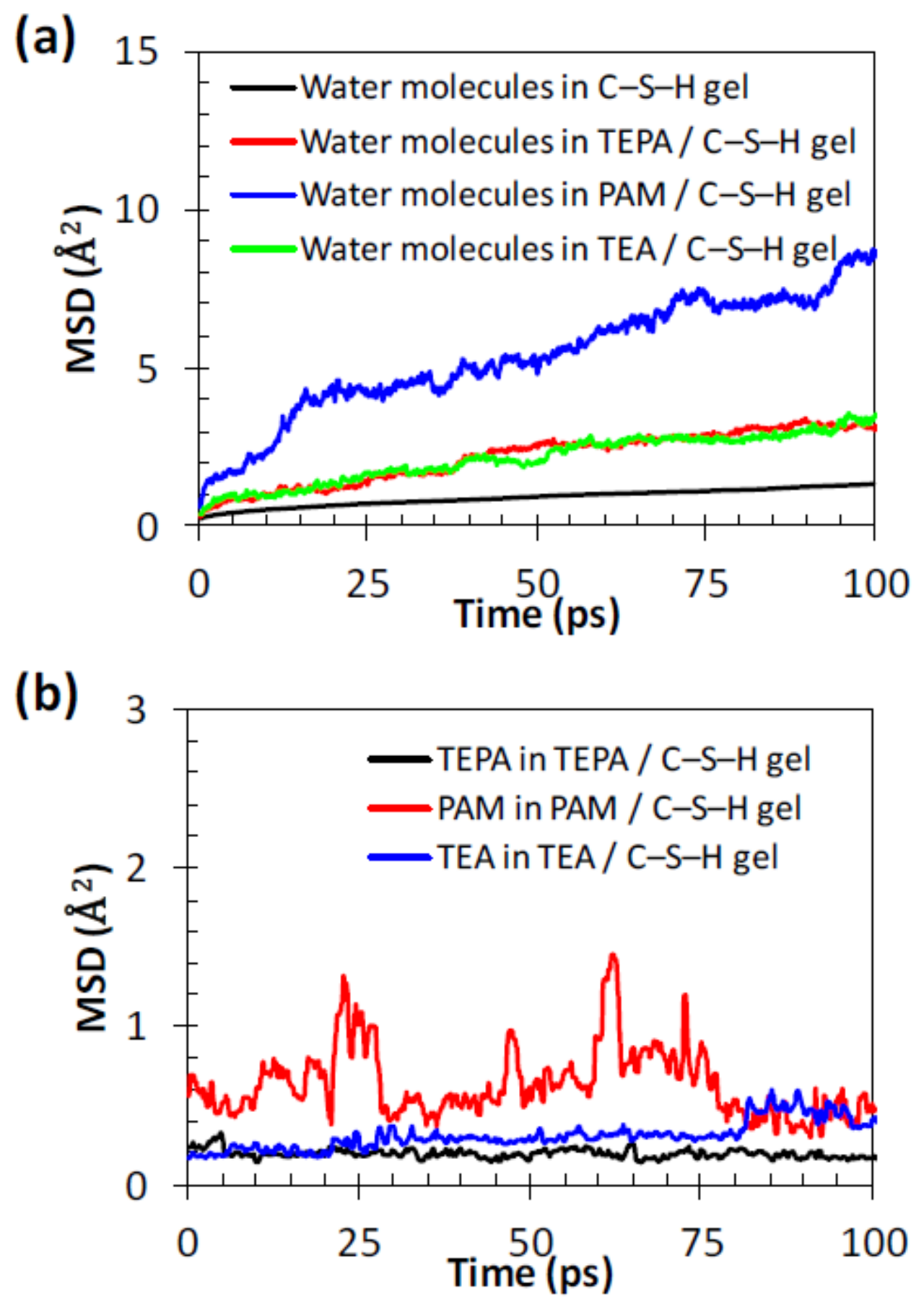

Figure 10

Evolution of mean square displacement for: (a) water molecules in C-S-H gel, TEPA / C-S-H gel, PAM / $\mathrm{C}-\mathrm{S}-\mathrm{H}$ gel and TEA / C-S-H gel, and (b) amine molecules in TEPA / C-S-H gel, PAM / C-S-H gel and TEA / C-S-H gel. 

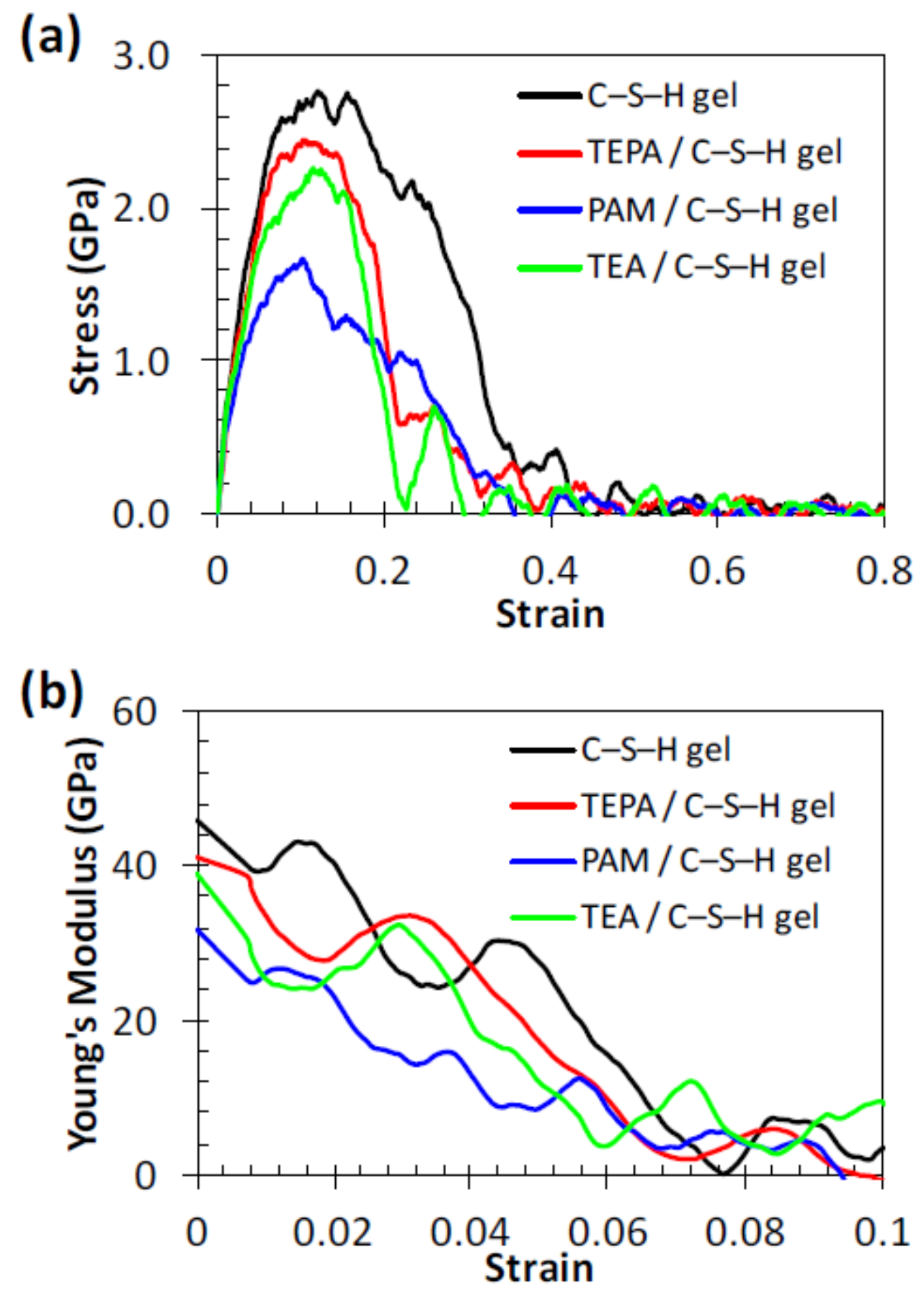

Figure 11

(a) Predicted stress-strain behaviors of in C-S-H gel, TEPA / C-S-H gel, PAM / C-S-H gel and TEA / C$\mathrm{S}-\mathrm{H}$ gel, and (b) the corresponding Young's modulus as a function of strain in (a). 


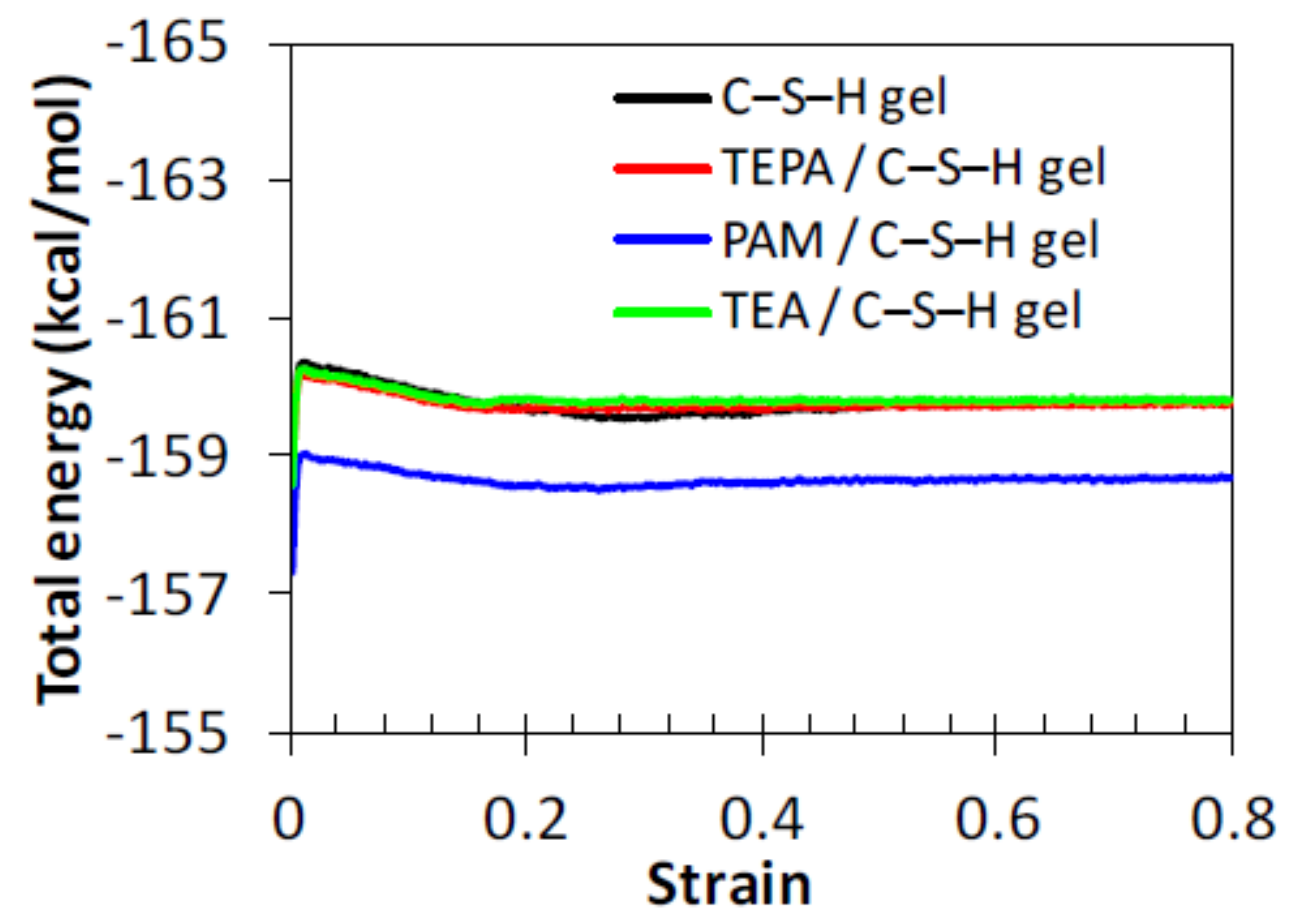

Figure 12

Variation of total energy as a function of strain. 

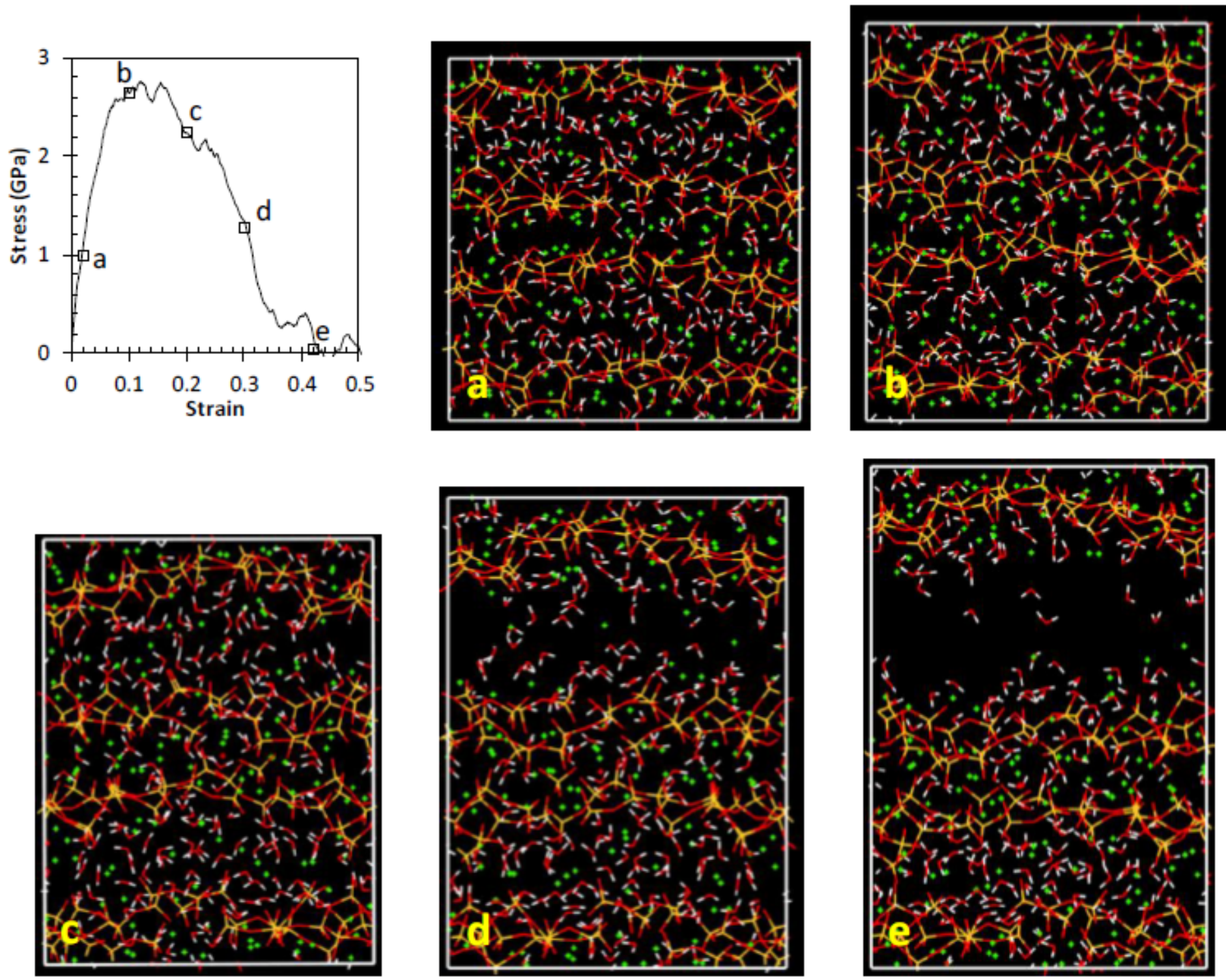

Figure 13

Predicted deformation and failure process in $\mathrm{C}-\mathrm{S}-\mathrm{H}$ gel at five different stages during a uniaxial tensile load. The five stages $(a-e)$ are indicated in the stress versus strain (one of the predicted curves in Fig. 11a). 

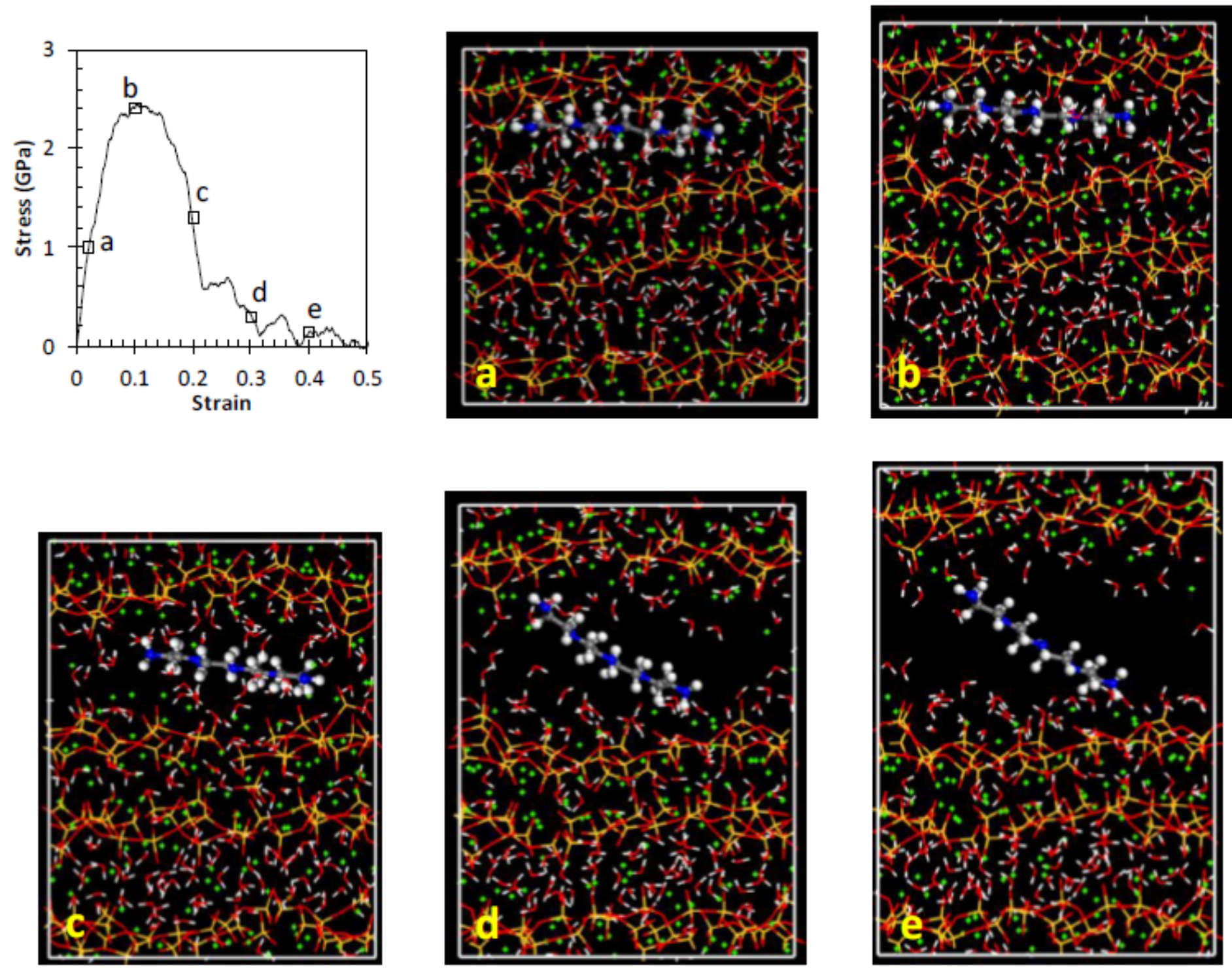

Figure 14

Predicted deformation and failure process in TEPA / C-S-H gel at five different stages during a uniaxial tensile load. The five stages $(a-e)$ are indicated in the stress versus strain (one of the predicted curves in Fig. 11a). 

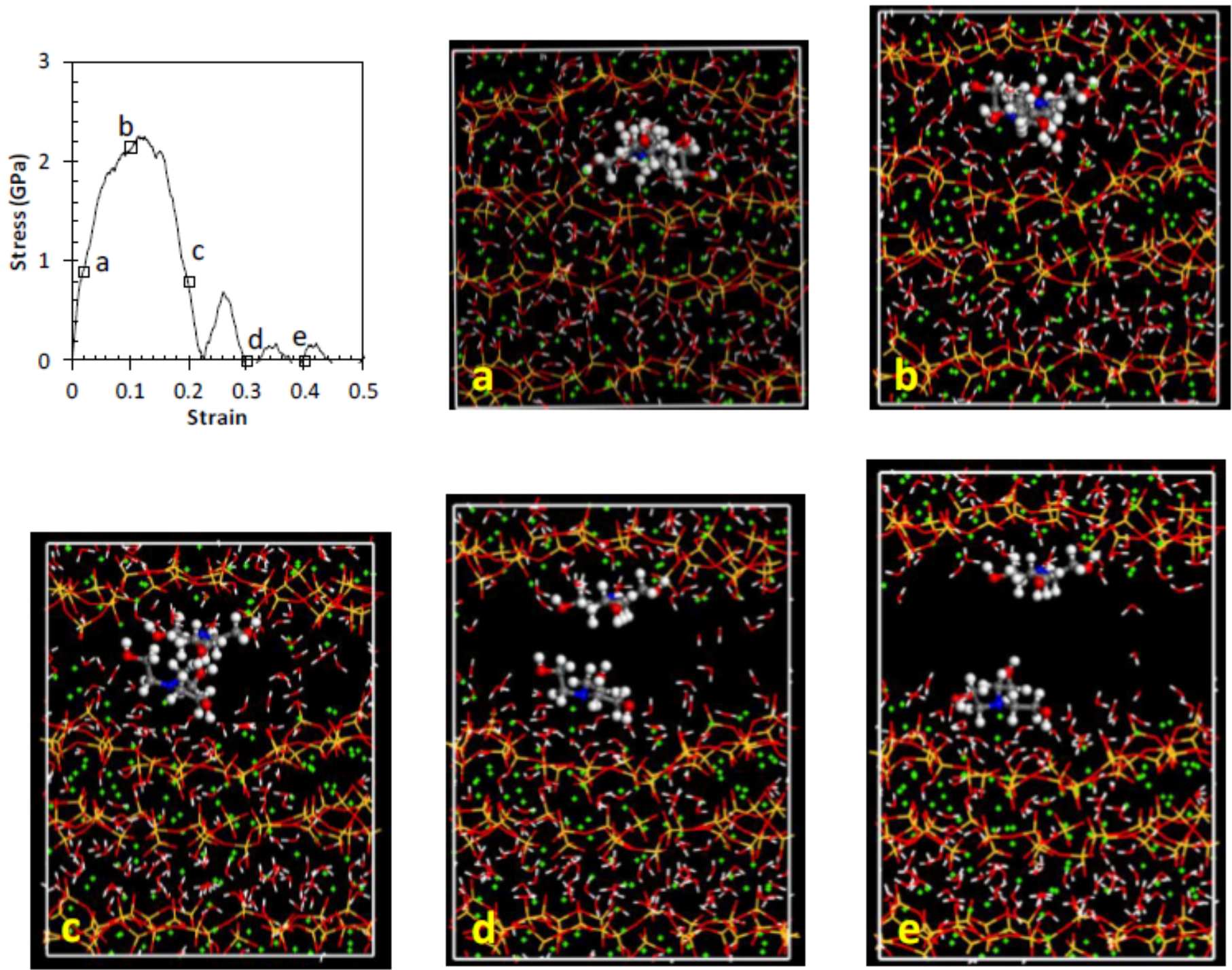

Figure 15

Predicted deformation and failure process in TEA / C-S-H gel at five different stages during a uniaxial tensile load. The five stages $(a-e)$ are indicated in the stress versus strain (one of the predicted curves in Fig. 11a). 

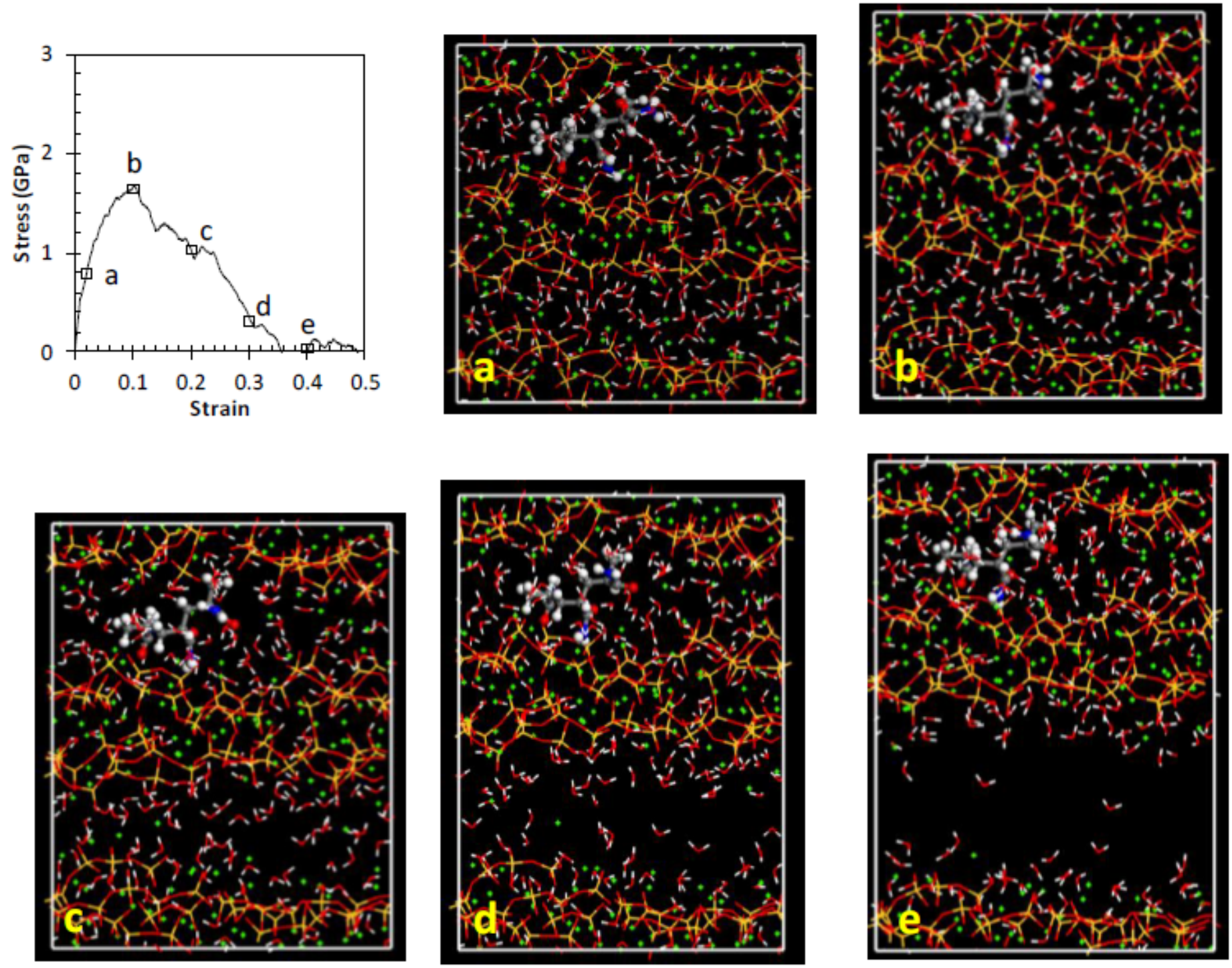

Figure 16

Predicted deformation and failure process in PAM / C-S-H gel at five different stages during a uniaxial tensile load. The five stages $(a-e)$ are indicated in the stress versus strain (one of the predicted curves in Fig. 11a). 